\title{
Do weak institutions prolong crises? : On the identification, characteristics, and duration of declines during economic slumps
}

Citation for published version (APA):

Bluhm, R., de Crombrugghe, D. P. I., \& Szirmai, A. (2013). Do weak institutions prolong crises? : On the identification, characteristics, and duration of declines during economic slumps. AFD/MGSoG Working Paper IPD-WP003 and UNU-MERIT 2013-069. UNU-MERIT Working Papers No. 069

Document status and date:

Published: 01/01/2013

Document Version:

Publisher's PDF, also known as Version of record

Please check the document version of this publication:

- A submitted manuscript is the version of the article upon submission and before peer-review. There can be important differences between the submitted version and the official published version of record.

People interested in the research are advised to contact the author for the final version of the publication, or visit the DOI to the publisher's website.

- The final author version and the galley proof are versions of the publication after peer review.

- The final published version features the final layout of the paper including the volume, issue and page numbers.

Link to publication

\footnotetext{
General rights rights.

- You may freely distribute the URL identifying the publication in the public portal. please follow below link for the End User Agreement:

www.umlib.nl/taverne-license

Take down policy

If you believe that this document breaches copyright please contact us at:

repository@maastrichtuniversity.nl

providing details and we will investigate your claim.
}

Copyright and moral rights for the publications made accessible in the public portal are retained by the authors and/or other copyright owners and it is a condition of accessing publications that users recognise and abide by the legal requirements associated with these

- Users may download and print one copy of any publication from the public portal for the purpose of private study or research.

- You may not further distribute the material or use it for any profit-making activity or commercial gain

If the publication is distributed under the terms of Article 25fa of the Dutch Copyright Act, indicated by the "Taverne" license above, 


\title{
UNU-MERIT Working Paper Series
}

\#2013-069

\author{
Do weak institutions prolong crises? \\ On the identification, characteristics, and duration of declines during \\ economic slumps \\ Richard Bluhm, Denis de Crombrugghe and Adam Szirmai
}

Working Paper Series on Institutions and Economic Growth: IPD WP17

This working paper is part of the research programme on 'Institutions, Governance and Long-term Economic Growth', a partnership between the French Development Agency (AFD) and the Maastricht Graduate School of Governance (Maastricht University - UNUMerit). The research builds on the Institutional Profiles Database IPD, jointly developed by AFD and the French Ministry of the Economy since 2001.

ISSN 1871-9872

Maastricht Economic and social Research institute on Innovation and Technology (UNU-MERIT) email: info@merit.unu.edu | website: http://www.merit.unu.edu Maastricht Graduate School of Governance (MGSoG) email: info-governance@maastrichtuniversity.nl | website: http://mgsog.merit.unu.edu 


\section{AFD-MGSoG/UNU-Merit Working Paper Series on " Institutions, Governance and Long term Growth »}

In 2010, the French Development Agency (AFD) initiated a partnership with the Maastricht Graduate School of Governance (Maastricht University - UNU-Merit) with a view to exploring the conceptual and econometric relationships between institutions and long-term growth. As a development bank with a long-term lending horizon, AFD is particularly interested in better understanding the determinants of countries' long term economic, social, and political trajectory.

AFD has thus developed a programme on "Institutions, Governance, and Long-term Growth" dealing with the five following dimensions:

(i) Measuring institutions and discussing the meaning of such measures, notably through the Institutional Profiles Database;

(ii) Testing the econometric relationship between institutional measures and long term growth;

(iii) Exploring through a series of country case studies the historical relationship between processes of economic accumulation, forms of political organisation, and social cohesion;

(iv) Discussing conceptual frameworks for making sense of the interaction between political, social and economic forces in the process of development;

(v) Developing methodologies for political economy analyses.

The MGSoG/UNU-Merit team is involved in the five dimensions with a particular focus on the first two. Its primary objective is to explore the Institutional Profiles Database jointly developed by AFD and the French Ministry of the Economy since 2001. Institutional Profiles Database is unique by its scope (about 350 elementary questions pertaining to all institutional dimensions covering 148 countries in 2012), its entirely free access, and its ambition to incorporate the most recent theoretical advances in the field of political economy.

The present series intends to convey the results of our ongoing research, and in so doing to reflect the wealth of issues that can be fruitfully addressed from an "institutionalist" perspective. We hope that readers will find these papers stimulating and useful to develop their own understanding and research.

Nicolas Meisel (AFD)

Adam Szirmai (MGSoG/UNU-Merit)

For more information on the programme, please visit our websites:

http://www.maastrichtuniversity.nl/web/Schools/MGSoG/ProjectPages/InstitutionalProfiles Database.htm

http://www.afd.fr/lang/en/home/recherche/themes-recherches/institutions-gouvernancecroissance 


\title{
Do Weak Institutions Prolong Crises?
}

\author{
On the identification, characteristics, and duration of declines during \\ economic slumps*
}

\author{
Richard Bluhm $^{\dagger} \quad$ Denis de Crombrugghe ${ }^{\ddagger} \quad$ Adam Szirmai $^{\S}$
}

December 2013

WORKING PAPER

\begin{abstract}
This paper defines economic slumps as sequences of structural breaks exhibiting a specific pattern. We identify 58 such episodes between 1950 and 2008 among 138 countries, and then examine the phases of decline and their duration. In some countries declines last extremely long, and we put several likely contributing factors to the test. We find evidence that weak institutions precede crises and, interestingly, positive reforms occur thereafter. Strong institutions shorten the duration of crises, ethnic cleavages do the reverse. However, the negative effects of ethnic cleavages are not insurmountable: an interaction effect suggests they can be offset by appropriate institutions.
\end{abstract}

Keywords: economic slumps, crises, institutions, structural breaks, duration analysis JEL Classification: O43, O11, C41, F43

${ }^{*}$ This paper has been presented at AFD (Paris, 2013), DIAL (Paris, 2013), NIPF-DEA (Delhi, 2013) and Ifo (Dresden, 2013) workshops/ conferences, as well as several workshops in Maastricht (2012-2013). We have greatly benefited from discussions with several participants. In particular, we would like to thank Agustín Casas, Ajay Shah, Bart Verspagen, Nicolas Meisel, Thomas Roca, and Kaj Thomsson. We gratefully acknowledge financial support from the Agence Française de Développement (AFD). The findings, interpretations and conclusions expressed in this paper are solely those of the authors and do not necessarily represent policies or views of the Maastricht Graduate School of Governance, UNU-MERIT, AFD and/or other affiliated institutions. All remaining errors are those of the authors.

${ }^{\dagger}$ Maastricht University, Maastricht Graduate School of Governance, UNU-MERIT, e-mail: richard.bluhm@maastrichtuniversity.nl

${ }^{\ddagger}$ Maastricht University, School of Business and Economics, Department of Quantitative Economics, e-mail: d.decrombrugghe@maastrichtuniversity.nl

${ }^{\S}$ UNU-MERIT, Maastricht University, Maastricht Graduate School of Governance, e-mail: szirmai@merit.unu.edu 


\section{Introduction}

The last sixty years of growth have been far from steady. For every "growth miracle" we can easily find a counterpart in the form of a "miraculous collapse". For example, the East Asian miracle was interrupted by the Asian financial crisis, China's take-off in 1978 was preceded by decades of disastrous economic policies, Latin America was frequently rocked by political turmoil and economic volatility, and several African nations went from "up and coming" in the 1950s to requiring outside assistance within a few years. Moreover, during the post-war period, there is a long list of relatively short-lived developed country crises including the first global recession in 1957, the global oil crisis in 1973-74, the debt crisis of 1982, and the Nordic banking crisis of the 1990s. What can we learn from such abrupt changes in growth? Do some countries deal better with negative growth shocks than others? Is the ability to respond effectively to shocks a key factor in explaining the long-run divergence in economic performance?

The instability of growth is not a new concern in economics. A growing literature on trend breaks has established that most growth performances are not steady but instead marked by switching between very different growth regimes. In this view, growth is no longer defined by a single average trend but consists of many qualitatively different episodes, such as crises, recoveries, stagnation, slows downs, and accelerations. This non-linear perspective provides better insights into the underlying dynamics and has established new stylized facts. For example, in developed and developing countries alike, growth is relatively easy to ignite (Hausmann et al., 2005) but much harder to sustain (Berg et al., 2012). However, the negative implications of unsteady growth paths are just beginning to be explored. Long-lasting slumps can nullify decades of positive growth and there is no guarantee that lost potential output after a slump is ever fully recouped (Cerra and Saxena, 2008; Reddy and Minoiu, 2009). It thus becomes important to ask, why do some declines last so much longer than others?

A potential answer is that the duration of declines during slumps is driven by the prevailing structure and quality of institutions. Institutions create particular political and economic incentives, solve or worsen coordination failures and define the set of feasible policies. Seminal contributions to the institutions and growth literature link stronger institutions to higher levels of GDP per capita (Acemoglu et al., 2001, 2002) and others have shown that strong institutions, democracy and political stability bring about reduced output volatility (Acemoglu et al., 2003; Mobarak, 2005; Klomp and de Haan, 2009). However, there is still a lack of evidence convincingly linking institutions to short and medium-run growth dynamics.

Each type of growth episode has distinct characteristics. We can analyze the switching among growth regimes, the rate of growth within a regime, the duration of a regime, or even the typical sequence of regime switches that makes up a growth path. Out of this plethora of possibilities, this paper focuses on three points. First, how can we identify large economic slumps empirically? Second, what happens when slumps occur? Specifically, is there any evidence of institutional change? Third, conditionally on the occurrence of a slump, do weak institutions prolong the duration of the decline phase?

We focus on this conditional question, as economic crises can be triggered by a variety of external or internal factors which are not (always) linked to weak institutions. However, how a country deals with a negative shock, that is, if the decline phase takes longer than necessary, depends on the political system's ability to react with coordinated policies and avert outright social conflict. This notion derives from a large body of 
political economy theory putting social tension and the ability of resilient institutions to manage such conflict at the center of development theory (e.g. Acemoglu and Robinson, 2006; North et al., 2009; Besley and Persson, 2011). Some of these theories argue that weakly institutionalized societies, or 'limited access orders', are prone to collapses and that, during a crises, the declining rents further strain the institutional set-up and the prevailing political arrangements (e.g. North et al., 2009). Weak institutions thus bring with them an increased vulnerability to crises and potentially much longer declines once slumps occur. Similar mechanisms are suggested in the literature on institutions and macroeconomic volatility. Acemoglu et al. (2003), for example, argue that institutions determine "whether there will be significant swings in the political and social environment leading to crises, and whether politicians will be induced to pursue unsustainable policies in order to remain in power in the face of deep social cleavages." (p. 54). So even if better policy responses are available, a combination of coordination failures, rent seeking and power struggles combined with dormant social conflict may lead to longer declines in weakly institutionalized environments. Hence, the interplay of institutions and social conflict plays out at a "deeper" level than more proximate responses to crises.

The findings of this paper broadly support this theoretical perspective. First, we find evidence of weaker institutions preceding the start of a slump and clear signs of institutional reforms in following years. Second, longer decline phases are robustly linked to weak institutions and particularly strongly to a measure of ethnic cleavages (ethnolinguistic fractionalization). Ethnic cleavages are especially important for understanding declines in Sub-Saharan Africa (see also Easterly and Levine, 1997). Third, we show that weak institutions and high fractionalization interact negatively. In weakly institutionalized and highly fragmented societies declines last considerably longer.

The remainder of this paper is structured as follows. Section 2 motivates and outlines the restricted structural change approach used to identify slumps and defines the duration of the decline phase. Section 3 provides descriptive statistics of the estimated slumps and very briefly discusses the data used in the subsequent analysis. Section 4 investigates the characteristics of slumps and the evolution of covariates before, during and after a slump occurs. Section 5 analyzes the duration of the decline phase and provides a substantive interpretation of the main results. Section 6 concludes.

\section{Identifying slumps}

\section{Restricted structural breaks}

Beginning with Pritchett's (2000) classification of post-World War II growth experiences into "Hills, Plateaus, Mountains, and Plains", a large and growing empirical literature sets out to investigate the characteristics of different types of growth episodes. Many of these papers employ either simple or more complex tests of structural stability to define and identify their episode of interest. For example, Hausmann et al. (2005) use economic criteria to isolate growth accelerations and then date their beginning with a very simple breakpoint test. Other authors, such as Jones and Olken (2008) and Berg et al. (2012), use versions of the Bai and Perron $(1998,2003)$ test for multiple unknown change points to classify different growth episodes. A third set of papers solely relies on economic criteria to identify and date the episode of interest (e.g. Calvo et al., 2006; Hausmann et al., 2008; Reddy and Minoiu, 2009).

Not every change in growth rates amounts to a regime switch. The main advantage 
of econometric tests for multiple structural breaks over any set of predefined economic criteria is that they allow for an inferential approach to identifying growth regimes. However, since the particular type of structural change is left unspecified, these tests may not identify the theoretically desired type of regime switch but rather any form of significant change which must then be classified ex post. Furthermore, while break estimators work well for identifying growth spurts, they perform poorly when it comes to identifying recessions or growth collapses. ${ }^{1}$ Methods based solely on deterministic economic criteria, on the other hand, cannot discriminate among multiple plausible starting points or assess whether an episode truly constitutes a departure from the previous growth regime.

To improve the identification of what we interchangeably refer to as deep recessions, slumps, or growth collapses, Papell and Prodan (2012) propose a two-break model with parameter restrictions. They demonstrate that this modified structural change approach consistently identifies well-known slumps, such as the Great Depression in the United States. The key innovation is to impose features of the desired pattern directly instead of searching for unrestricted structural changes. Their two-break model accounts for three growth regimes (a pre-slump regime, a contraction/ recovery regime, and a post-slump regime) and places sign restrictions onto the estimated coefficients to ensure the breaks occur in the desired direction. Since this approach is a version of Bai's (1999) sequential likelihood ratio test, the number of slumps - which is not known in advance - can then be estimated by recursively applying the model on ever smaller sub-samples until all breaks in the GDP per capita series have been found.

The restricted structural change approach can easily be modified to allow for other plausible structures, such as three-break models (e.g., to estimate a pre-slump regime, a decline, a recovery and a post-slump regime). However, estimating three or more breaks for each slump quickly becomes computationally expensive and does not necessarily provide better results than a simpler two-break model. ${ }^{2}$ While Papell and Prodan (2012) focus on the question whether growth in a few developed countries eventually returns to its pre-slump trend path, we apply a variant of this method to identify slumps in a large sample of countries over the period from 1950 to 2008.

We define slumps according to three intuitive criteria. First, a slump is a departure from a previously positive trend. Second, a slump must begin with negative growth in the first year. Third, all slumps should be pronounced regime switches and not just minor business cycle fluctuations. The precise meaning of 'pronounced' depends on each country's idiosyncratic growth process. We do not impose a minimum depth.

We capture these criteria in the following partial structural change model:

$$
y_{t}=\alpha+\beta t+\gamma_{0} \mathbf{1}\left(t>t b_{1}\right)+\gamma_{1}\left(t-t b_{1}\right) \mathbf{1}\left(t>t b_{1}\right)+\gamma_{2}\left(t-t b_{2}\right) \mathbf{1}\left(t>t b_{2}\right)+\sum_{i=1}^{p} \delta_{i} y_{t-i}+\epsilon_{t}
$$

where $y_{t}$ is the log of GDP per capita, $\beta$ is a time trend, $\gamma_{0}$ is the coefficient on an intercept break occurring together with a trend change $\left(\gamma_{1}\right)$ after the first break at time $t b_{1}, \gamma_{2}$

\footnotetext{
${ }^{1}$ As Papell and Prodan (2012) point out, this applies to the entire class of "generic" tests for single and multiple breaks (Andrews, 1993; Bai and Perron, 1998, 2003; Perron and Qu, 2006).

${ }^{2}$ Let $q=T-2 \tau T-h$, where $\tau$ is the trimming fraction and $h$ is the distance between breaks, then the two-break model estimates $\left(q^{2}+q\right) / 2$ regressions for the first iteration, while a three-break model already requires $\sum_{i=1}^{q}\left(i^{2}+i\right) / 2=(1 / 12) q(q+1)(2 q+4)-1$, with $q=T-2 \tau T-2 h$ to now allow for three breaks. Additional results are available on request.
} 
is the coefficient for a second trend change occurring after the second break at time $t b_{2}$, $\mathbf{1}(\cdot)$ is an indicator function selecting the regime, $p$ is the optimal lag order determined by the Bayesian information criterion (BIC) to parametrically adjust for the presence of serial correlation, and $\epsilon_{t}$ is a martingale difference sequence such that $\mathrm{E}\left[\epsilon_{t} \mid \mathcal{F}_{t-1}\right]=0$ with $\mathcal{F}_{t-1}=\left\{y_{t-1}, y_{t-2}, \ldots\right\}$ representing the entire history of the series.

The model in equation (1) formalizes the notion that the evolution of GDP per capita around a slump is a simple function of time split into three different growth regimes: (1) a pre-slump regime from the beginning of the time series of a country until time $t b_{1},(2)$ a slump/recovery regime lasting from time $t b_{1}+1$ to time $t b_{2}$, and (3) a post-slump regime from time $t b_{2}+1$ onwards. The true location of the breakpoints is not assumed known but estimated within the model. We impose two restrictions to make sure we only select breaks meeting our definition of slumps. First, we require $\beta>0$, so that growth must be positive in the years before a slump begins. Second, we also impose the condition that $\gamma_{0}<0$, so that a slumps always starts with a drop in the intercept. ${ }^{3}$ Slope shifts are left unrestricted, so that the model can catch unfinished slumps (e.g., declines from $t b_{1}$ onwards, possibly lasting until the end of a country's time series).

We implement the sequential break search algorithm as follows. First, we fit the structural change model specified in equation (1) for all possible combinations of $t b_{1}$ and $t b_{2}$. We always exclude $5 \%$ of the observations at the beginning and end of the sample to avoid registering spurious breaks. Second, we compute the sup- $W$ test statistic, that is, the supremum of a Wald test of the null hypothesis of no structural change $\left(\mathbb{H}_{0}: \gamma_{0}=\gamma_{1}=\gamma_{2}=0\right)$ over all possible combinations of break dates satisfying the two restrictions. Third, we bootstrap the empirical distribution of the sup- $W$ statistic (see below). If the bootstrap test rejects at the $10 \%$ significance level, we record the break pair $\left(\widehat{t b}_{1}, \widehat{t b}_{2}\right)$ and split the sample into a series running until the first break and a series starting just after the second break. The process starts again on each sub-sample until the bootstrap test fails to reject the null hypothesis of no breaks or the sample gets too small. ${ }^{4}$ This procedure converges to the true number of breaks (Bai, 1997).

A key issue in evaluating the statistical significance of endogenous breakpoints is that the individual Wald tests over which the sup- $W$ statistic is computed are not independent. Assuming that there are in fact breaks present in the series, the closer the estimated break dates get to the true breakpoints, the higher the test statistic will be, and vice versa. For several single and multiple change-point problems, the limiting distribution of the sup- $W$ statistic or similar test statistics taking this dependency into account has been derived (Andrews, 1993; Andrews and Ploberger, 1994; Bai, 1997, 1999; Bai and Perron, 1998; Hansen, 2000). However, asymptotic tests tend to underreject in finite samples (Prodan, 2008) and an asymptotic distribution for our particular version of restricted structural change is not available. To circumvent both issues, we construct a bootstrap Monte Carlo test as follows. We first estimate the optimal $\operatorname{AR}(p)$ model under the null hypothesis of no structural change. Then, we draw new errors $\left(\hat{e}_{t}^{*}\right)$ from a standard normal distribution with variance equal to that of the residuals estimated by the optimal model under the null (denoted $\left.\sigma_{\hat{e}}^{2}\right)$, so that $\hat{e}_{t}^{*} \sim \mathcal{N}\left(0, \sigma_{\hat{e}}^{2}\right)$. Next, we recursively construct a bootstrap series $\left(y_{t}^{*}\right)$ based on the parameters estimated under the null together with the new error series $\left(\hat{e}_{t}^{*}\right)$. Using this bootstrap series, we then re-run the break search algorithm and compute the sup- $W$ statistic in exactly the same manner as before. We

\footnotetext{
${ }^{3}$ The intercept shift implies that we assume that there is an instantaneous drop. However, by not restricting the coinciding trend break we also allow for longer lasting declines.

${ }^{4}$ We stop when $T \leq 20$ to avoid registering spurious breaks.
} 
repeat this process 1000 times. Adopting the $10 \%$ significance level, the critical value for each estimated sup- $W$ statistic is then located at the $90^{\text {th }}$ percentile of all recorded bootstrapped sup- $W$ statistics. Appendix A gives a more formal description of the break search algorithm and the bootstrap.

The structural break methods applied in this paper assume that GDP per capita is a regime-wise trend stationary process. This is not a trivial requirement. Ever since the issue was first raised by Nelson and Plosser (1982), a vibrant literature has been debating the question whether most GDP series are unit-root processes or can be considered trend stationary. Originally, the conflicting views evolved around a clear divide. If an output series is non-stationary, i.e., it has a unit root, then any shock to the economy is permanent. If the series is trend stationary, then shocks are temporary; after a while GDP is back on track as if the shock never occurred. ${ }^{5}$ Given the available data, this issue cannot be fully resolved. It is generally difficult - if not impossible - to convincingly differentiate between non-stationary and stationary time series when $T$ is only moderately large.

More recently, however, the debate has shifted. A process that is subject to structural breaks presents an intermediate case. Broken-trend stationarity only implies that within each regime growth can be approximated by a deterministic trend, but from one regime to the next the trend path may change due to (semi-)permanent shocks such as big recessions, growth accelerations or growth slow-downs. This allows for a flexible description of the growth process as several different types of trend breaks can occur. In fact, there is mounting evidence that once trend breaks are incorporated, many of the GDP series previously thought to have unit roots may in fact be broken-trend stationary (e.g. Zivot and Andrews, 1992; Ben-David and Papell, 1995). Broken trends blur the conceptual distinction. A unit root process can be thought of as process with a trend that changes every year. ${ }^{6}$

We do not attempt in this paper to characterize all types of breaks an economy can experience, or to formally test for unit roots. Our approach is very flexible and allows for multiple growth regimes occurring before, during and after an unknown number of slumps. We assume that there is some structure in the growth process, but do not assume that this structure is necessarily generated by neoclassical steady-state growth, endogenous growth or other standard growth models. In fact, Aguiar and Gopinath (2007) recently highlighted that growth in emerging markets can be characterized by shocks to trend growth rather than transitory fluctuations around a stable trend as usually assumed in real business cycle models. Hence, under certain conditions, broken trends are compatible with several standard models of aggregate output.

\section{The duration of declines}

Within a slump, we separate the decline from the recovery phase, as these two processes are driven by very different dynamics. We still need an estimate of the location of the

\footnotetext{
${ }^{5} \mathrm{~A}$ unit root process, such as a random walk with drift, can be written as $y_{t}=y_{t-1}+\mu+\epsilon_{t}$, whereas a trending process is $y_{t}=\beta t+\epsilon_{t}$. A random shock $\epsilon_{t}$ is incorporated permanently in the unit root process but not in the trending process. However, this is embedded in the larger question of the degree of fractional integration in GDP series (see Silverberg and Verspagen, 2003, for a discussion).

${ }^{6}$ Every year, or at any other observation frequency. For the same reason, it is easy to weaken the evidence in favor of a unit root process and strengthen the evidence in favor of a broken-trend stationary process as long as enough breakpoints are permitted.
} 
trough in order to actually identify the decline phase. Our method of dating the trough is simple and only depends on whether the slump is finished or still continuing.

We define the end of a slump to have occurred with certainty in the first year $a$ where $y_{a} \geq y_{\widehat{t b}_{1}}$. In other words, a slump is over as soon as the level of GDP per capita preceding the slump has been recovered; until then, the slump is continuing. ${ }^{7}$ It is important to note that the end of the slump does not coincide with the second break and is used only as a device to find the trough. Given this endpoint, the trough is simply the year with the lowest level of GDP per capita during the slump. The duration of the slump is censored if GDP per capita does not reach the pre-slump level again by the end of the sample. In such a case, even if GDP per capita seems to be recovering, we do not know how long the slump may last. We define the censoring indicator $c=\mathbf{1}\left(\max _{j \in\left(\widehat{t b}_{1}, T\right]} y_{j}<y_{\widehat{t}_{1}}\right)$. Given the set of possible end years $A=\left\{a \mid a \in\left(\widehat{t b}_{1}, T\right]\right.$ and $\left.y_{a} \geq y_{\widehat{t b}_{1}}\right\}$, we estimate the trough to occur at time:

$$
t_{\text {min }}= \begin{cases}\operatorname{argmin}_{j \in\left(\widehat{t b}_{1}, a_{0}\right]} y_{j}, & \exists j \in A \wedge c=0 \\ \operatorname{argmin}_{j \in\left(\widehat{t b}_{1}, T\right]} y_{j}, & \nexists j \in A \wedge c=1\end{cases}
$$

where $a_{0}=\min A$ corresponds to the (certain) end of the slump. If the set $\mathrm{A}$ is empty, then the slump is unfinished, and the length of the episode is censored. A provisional trough occurs when $y_{t}$ attains a minimum after $\widehat{t b}_{1}$. The duration of the decline phase lasting from the beginning of the slump to the observed trough is simply $\tilde{t}_{D}=\hat{t}_{\text {min }}-\widehat{t b}_{1}$.

These definitions also imply that in some cases we date the trough after the estimated second break, which is purely a consequence of allowing for unfinished episodes. If the slump is still ongoing, the second break may have been placed at an arbitrary point maximizing the Wald statistic but not corresponding to the start of a new growth regime. ${ }^{8}$ The true trough may lie in the future, that is, beyond the end of the sample. Treating such spells as censored implies that in the later analysis we only incorporate the information that (certain) exit from the slump has not yet occurred after a duration $\tilde{t}_{D}$.

Figure 1 illustrates some of the diversity of slumps identified by this method. Panel (a) shows a finished slump in Mexico where the trend growth rate is nearly unchanged after the slump. The slump begins in 1982 and encompasses more than a decade of political volatility, hyperinflation, high debt and low growth. The trough is found in 1988. Another short downturn occurs during the Tequila crisis in 1994 after which the Mexican economy returns to its pre-1982 growth path. Panel (b) shows a finished slump in Switzerland where the trend growth rate decelerated after the slump. In 1975, the Swiss economy was strongly affected by the Oil crisis of the mid-1970s, leading to a $7.87 \%$ drop in GDP per capita within one year. After the slump, Switzerland enters a low growth regime typical for the high income economies in Western Europe of the 1980s and 1990s. Panel (c) shows a finished slump in Albania occurring at the time of the post-communist transition with an accelerated post-slump trend. The estimated first break occurs in 1990, the trough is located in 1991, and the second break occurs in 2002. While the duration of the decline phase is only one year, output contracted considerably. GDP per capita in 1991 was $15.32 \%$ lower than in 1990. Last but not least, panel (d) shows an unfinished slump with a continuing decline in Togo. Togo grew rapidly for over

\footnotetext{
${ }^{7}$ Naturally, this also implies that we exclude episodes estimated by the sequential algorithm if these begin before the previous slump is certain to have ended.

${ }^{8} \mathrm{~A}$ solution avoiding this problem would be to test if a restricted one break model works better than a restricted two-break model for those cases.
} 
Figure 1 - Four types of slumps

(a) finished \& unchanged trend

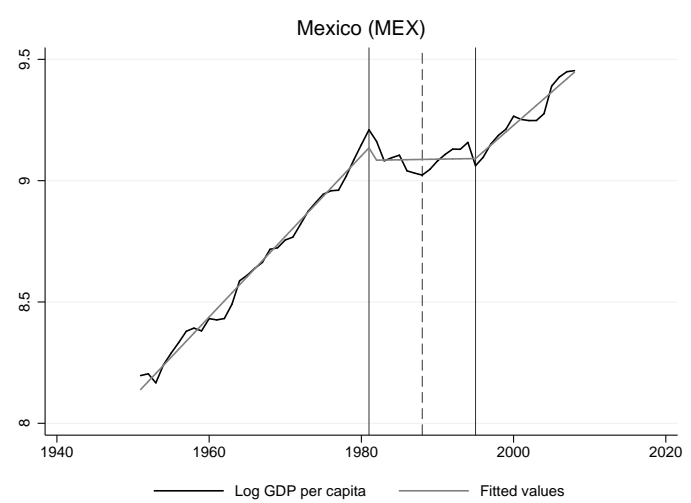

(c) finished \& accelerated trend

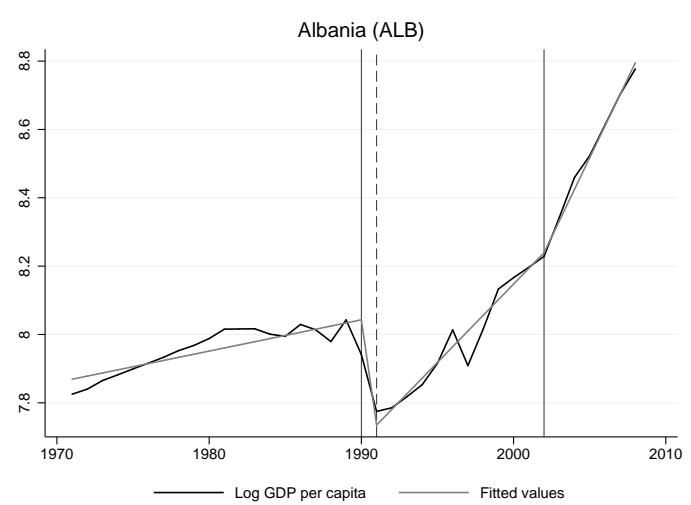

(b) finished \& decelerated trend

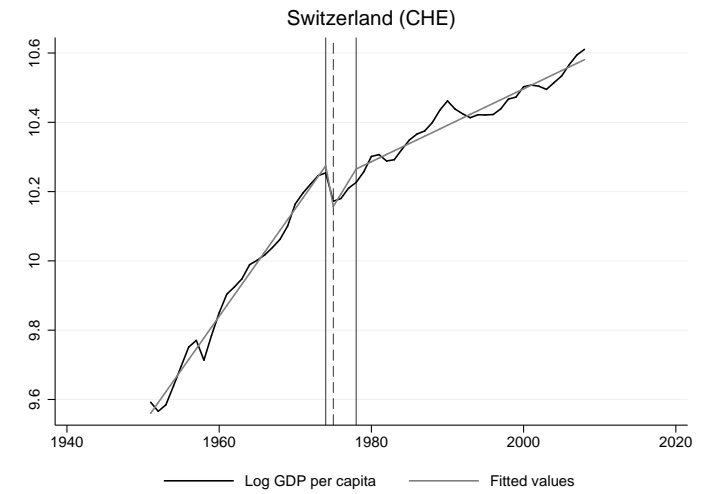

(d) unfinished \& negative trend

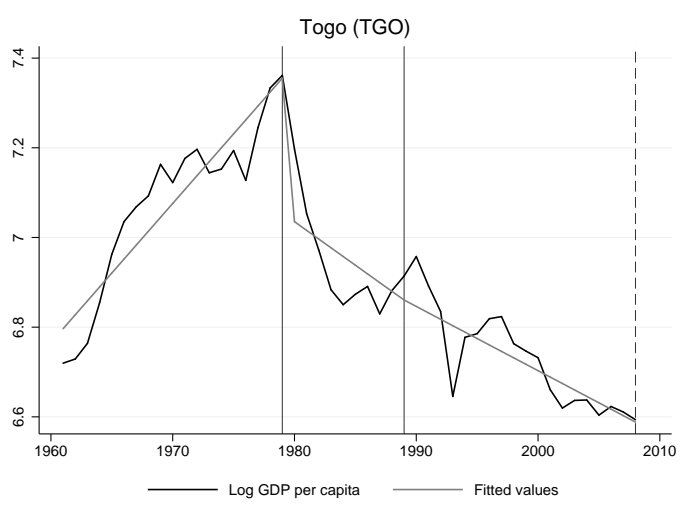

Note $(s)$ : Models refitted using the estimated breaks $\widehat{t b}_{1}$ and $\widehat{t b}_{2}$ but without the optimal $\operatorname{AR}(p)$ terms to emphasize the trend breaks. The bold vertical lines are at $\widehat{t b}_{1}$ and $\widehat{t b}_{2}$, respectively. The dashed vertical line indicates $\widehat{t}_{\text {min }}$.

a decade following independence from France in 1960 but then experienced a dramatic collapse under the 38-year reign of Gnassingbé Eyadéma. The first break occurs in 1979, but the second break is placed at an (economically) arbitrary point to accommodate the lasting decline. Togo's GDP per capita did not recover to its pre-slump level for the next 29 years. At the end of the observed period, the decline is ongoing and the provisional trough coincides with the censoring cutoff in 2008. It's the longest decline in the sample and also one of the steepest $(-53.6 \%)$.

\section{$3 \quad$ Descriptive statistics and data}

We apply the sequential algorithm to the entire Penn World Table (v7.0) yielding a total of 58 slumps between 1950 and $2008 .^{9}$ The mean duration from the first break to the

\footnotetext{
${ }^{9}$ We only run the algorithm on countries with a population of at least one million to exclude small countries and island economies. In addition, we discard episodes that are solely driven by positive breaks in the two slope coefficient(s) but are not caught by our second criterion (negative growth) due to the presence of the $\operatorname{AR}(p)$ terms. A simple rule is applied to these cases. We define a valid episode as an interval of two break dates $\widehat{t b}_{1}, \widehat{t b}_{2} \in[\tau T,(1-\tau) T]$ satisfying: $\exists j \in\left(\widehat{t b}_{1}, \widehat{t b}_{2}\right]$ such that $\min y_{j}<y_{\widehat{t b}_{1}}$,
} 
trough is about 7.7 years and the median duration is 3 years. Ten out of the 58 slumps are censored and thus unfinished. For these spells the location of the trough is not yet definitive. Table 8 in Appendix B lists all episodes and provides summary statistics.

We observe several well-known growth collapses and deep recessions. For example, in the case of the Finnish banking crisis of the 1990s, we estimate that the last year of the previous growth regime is 1989, the first year of the slump is 1990 and the trough occurs in 1993. ${ }^{10}$ Chile's tumultuous economic history shows up in several big slumps. Pinochet's coup, the subsequent reform programs, and chronic runaway inflation manifested themselves once in a sudden recession in 1975 and again in a deep but short slump in 1982-1983. We also identify several post-communist transitions, but for most former communist countries there is no or too few pre-1990 GDP data available. Some results are more surprising. For example, Poland's economic downturn already occurs during the 1980s and is not fully recovered by the time the transition takes place.

Figure 2 - Distribution of Downbreaks (calendar time)

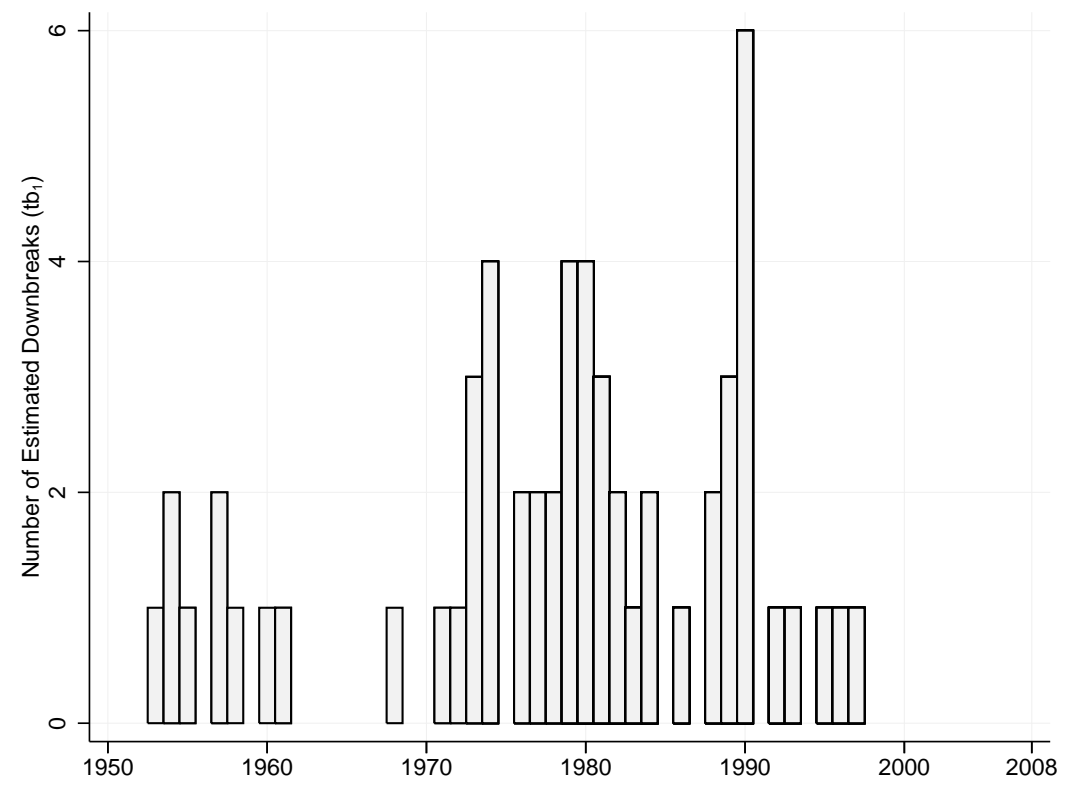

Which periods or decades experienced the most turbulence? Figure 2 examines the annual distribution of the the first break date $\left(\widehat{t b}_{1}\right)$ over the entire sample range (called 'downbreaks'). Most slumps begin between the 1970s and the early 1990s. We can clearly observe three periods of elevated risk coinciding with well-known global events. Seven downbreaks occur following the oil shock in 1973-1974, eleven declines begin between 1979 and 1981 during the debt crisis of the early 1980s, and nine slumps follow the postcommunist transitions of 1989-1990. Due to trimming and a deliberate sample cut-off in 2008 to avoid the Great Recession of the late 2000s, we find no beginnings of slumps in the period of the early 2000s and tranquil mid-2000s. Similarly, there are only few slumps in the 1960s but several more in the 1950s, with three slumps beginning around the time of the first post-WWII global recession of 1957. Generally, the period between

where $\tau$ is the trimming fraction and $T$ is the length of the estimation sample. This rule only requires that a contraction occurs within the range of the two estimated breaks, otherwise it is not a slump.

${ }^{10}$ This agrees well with other estimates (Jonung and Hagberg, 2005). The Finnish crisis is typically dated to occur between 1991-1993, but GDP actually started to decline in 1990 already. 
the 1970s and early 1980s is marked by heightened volatility during which several star performers of the previous years become mired in deep recession - an instability of growth performances across decades that is well-documented in a number of studies (Easterly et al., 1993; Rodrik, 1999; Pritchett, 2000; Jones and Olken, 2008).

Table 1 provides two additional perspectives on the data by summarizing the distributions of depth, duration, and number of spells across income groups and geographical regions. For this purpose, we define the depth of a decline as the percent decrease of GDP per capita at the trough relative to its pre-slump level. We detect considerably deeper slumps in low-income and middle-income countries than in highincome (OECD) countries. The spread of depth and duration is very large. Highincome (OECD) countries experience relatively short declines with a comparatively soft landing. The median duration is only one year with a mean depth of about $-7.1 \%$. In the middle, there is little substantial variation between non-OECD high-income countries and upper/lower-middle-income countries. In all of these three groups, the mean depth is in the range of $-20.8 \%$ to $-27.4 \%$ and the median (mean) duration varies between about 5.4 to 6 (2 to 3 ) years. Low-income countries experience the most dramatic declines. Both mean and median duration are about 16 years, with an associated average depth of $-34.2 \%$. Interestingly, the number of spells itself is distributed relatively evenly across the different income groups, suggesting that developed countries, too, experience their fair share of (milder) volatility.

Table 1 - Depth and Duration by Income Level and Geographical Region

\begin{tabular}{|c|c|c|c|c|c|c|}
\hline & $\begin{array}{c}\text { Mean } \\
\text { Depth }\end{array}$ & $\begin{array}{c}\text { Mean } \\
\text { Duration }\end{array}$ & $\begin{array}{c}\text { Median } \\
\text { Duration }\end{array}$ & $\begin{array}{l}\text { Number } \\
\text { of Spells }\end{array}$ & $\begin{array}{c}\text { Censored } \\
\text { Spells }\end{array}$ & $\begin{array}{c}\text { Number of } \\
\text { Countries }\end{array}$ \\
\hline \multicolumn{7}{|l|}{ Income Level } \\
\hline High Income (OECD) & -7.12 & 2.00 & 1 & 12 & 0 & 29 \\
\hline High Income (Other) & -20.84 & 5.38 & 2 & 8 & 1 & 12 \\
\hline Upper Middle Income & -21.20 & 5.39 & 2 & 16 & 2 & 30 \\
\hline Lower Middle Income & -27.40 & 6.00 & 3 & 11 & 3 & 34 \\
\hline Low Income & -34.17 & 15.75 & 16 & 11 & 4 & 33 \\
\hline \multicolumn{7}{|l|}{ Geographical Region } \\
\hline East Asia \& Pacific & -13.63 & 2.30 & 2 & 10 & 0 & 17 \\
\hline Eastern Europe \& Central Asia & -19.70 & 3.40 & 2 & 5 & 0 & 10 \\
\hline Europe (excl. Eastern Europe) & -8.37 & 1.50 & 1 & 6 & 0 & 22 \\
\hline Latin America \& Caribbean & -17.34 & 5.27 & 3 & 15 & 1 & 23 \\
\hline Middle East \& North Africa & -33.24 & 8.66 & 9 & 7 & 3 & 17 \\
\hline North America & -2.51 & - & - & 1 & 0 & 2 \\
\hline South Asia & -5.33 & - & - & 1 & 0 & 6 \\
\hline Sub-Saharan Africa & -37.14 & 17.74 & 16 & 13 & 6 & 41 \\
\hline Total & -21.87 & 7.69 & 3 & 58 & 10 & 138 \\
\hline
\end{tabular}

The geographical distribution reveals three interesting patterns. First, Sub-Saharan Africa and the Middle East \& North Africa are the two regions experiencing both the deepest and longest declines. The depth in these regions is particularly striking in comparison to the other regions. The mean decline is $-37.1 \%$ in Sub-Saharan Africa and $-33.2 \%$ in the Middle East \& North Africa, which is about double of the average 
decline in Latin America \& the Caribbean. The duration is longest in Sub-Saharan Africa, with the median spell lasting 16 years and the mean spell lasting over 17 years. Declines are shorter in the Middle East \& North Africa, where the mean and median do not exceed 9 years. Both regions also have the most censored/unfinished spells due to their long duration. Second, countries in Latin America \& the Caribbean experienced slumps most frequently, but the average decline was only moderately deep and lasted for about 5 years. Third, when comparing Eastern Europe \& Central Asia to the East Asia \& Pacific region we find similar mean and median durations but much deeper slumps in the former. ${ }^{11}$ As expected, there are comparatively few, short and mild declines in North America, Europe (excluding Eastern Europe), and - more surprisingly - South Asia.

Overall, Table 1 suggests a relatively strong association of both the mean duration and mean depth of the decline phase with different income levels. This is particularly interesting, since we subsequently model these observed differences in duration between high and low income economies with more fundamental factors such as institutions and ethnic fractionalization. Furthermore, the table provides a preliminary indication that there is substantial regional heterogeneity which will have to be taken into account in the ensuing analysis.

For brevity and since most of the additional data sources are well-known, we do not separately discuss the construction and summary statistics of the covariates used in the following sections. We include four major categories of variables: 1) a variety of measures for different aspects of institutions, politics and social conflict, 2) macroeconomic indicators of prices, trade and exports, 3 ) a set of variables for domestic and international finance, and 4) several other growth determinants (such as life expectancy or years of schooling). Table 9 in Appendix $\mathrm{C}$ provides an exhaustive list of all variable names, data sources and a basic set of summary statistics for the data used throughout the paper. Not all data is necessarily satisfactory but, in some cases, simply the best available. For example, we use the Polity IV database as our primary proxy for institutional development because of a lack of other time series data capturing the characteristics of political and economic institutions. Similarly, cross-country inequality data are notoriously flawed. Inequality data are usually drawn from household surveys of varying quality whose underlying welfare concepts are not strictly comparable. We rely on a data set compiled by Solt (2009) that standardizes inequality measures obtained from various sources in order to increase comparability and coverage. We describe other noteworthy features of the data in the discussion of the results.

\section{The anatomy of slumps}

Do some covariates show a systematic pattern of change just before the downbreak and after? Revealing the factors correlated with downbreaks serves two purposes. First, it highlights the characteristics of the slumps in our sample. Second, it indicates which variables may play a larger role in the duration analysis. In particular, we show that there is evidence of (endogenous) institutional change occurring during slumps.

To study these questions we employ an event methodology often used in the literature on currency and banking crises (Eichengreen et al., 1995; Kaminsky and Reinhart, 1999; Gourinchas and Obstfeld, 2012). The basic idea is to use dummy variables indicating a

\footnotetext{
${ }^{11}$ This is clearly driven by a few Eastern European transition economies. In our sample, this only refers to Albania, Bulgaria, Hungary, and Poland.
} 
pre-defined imminence to the start of the slump as a means of detecting changes in the relative mean of each time-varying covariate. Then, the coefficients of these "imminence dummies" measure if and how much these covariates change around the time the slump hits and their standard errors quantify the associated uncertainty.

We run the following regression for each time varying covariate $\left(x_{i t} \in \mathbf{x}_{i t}\right)$ :

$$
x_{i t}=\sum_{s=-5}^{5} \delta_{t, \widehat{t b}_{1}+s} \beta_{s}+\mu_{i}+\epsilon_{i t}
$$

where $\delta_{t, \widehat{t}_{1}+s}$ is the Kronecker delta which is equal to one if $t=\widehat{t b}_{1}+s$ and zero otherwise, $\beta_{s}$ are coefficients, $\mu_{i}$ is an unobserved country effect and $\epsilon_{i t}$ is an idiosyncratic error term. We set $s \in[-5,5]$, so that the result is an 11-year window around the break date $\widehat{t b}_{1}$. The first year of the slump is $s=1$ or $t=\widehat{t b}_{1}+1$.

The results are best reported visually by plotting the estimates of the coefficients $\beta_{s}$ (including 95\% confidence bands) as they represent the conditional expectation of the covariate $x_{i t}$ at time $s$ relative to "normal" times. ${ }^{12}$ In other words, we plot the countrydemeaned expectations of each indicator over 11 years around the downbreak $\left(\widehat{t b}_{1}\right)$.

We do not include time dummies to purge the cross-sectional dependence but allow the point estimates to capture shocks common to all countries. Instead, we compute standard errors that are robust to heteroskedasticity and autocorrelation among both country and time clusters using the formulas suggested by Thompson (2011) and Cameron et al. (2011). ${ }^{13}$ The confidence bands thus allow for common year shocks in each of these variables as well as within country correlation.

Figure 3 summarizes the evolution of output growth and (relative) prices. Before the beginning of a slump, growth is only marginally elevated relative to normal times, suggesting that - on average - the countries in our sample are not experiencing a growth acceleration just before the downbreak occurs. In the first year of the slump, growth is $13.7 \%$ less relative to normal times and remains depressed in the five years after, varying between $-2 \%$ and $-3 \%$ from years two to five. Similarly, an estimate of the output gap also shows that growth is not exceptionally strong before a slump. The output gap is close to normal levels during the four years preceding the downbreak. Then, once the slump occurs, output remains below potential in the five years after the break and is still $1.3 \%$ below potential in year five. We use a standard Hodrick-Prescott filter to estimate the output gap. HP filters have the downside of adjusting potential output downwards relatively quickly in advance of large slumps, thus creating the artificial spike at $s=0$.

Turning to consumer prices and exchange rates, Figure 3 shows that inflation is slightly elevated in the five years before the downbreak but this trend is insignificant. However, inflation strongly and significantly increases during the slump, peaking at 6-7\% above the median inflation rate during normal times in the first two years of decline. While this

\footnotetext{
${ }^{12}$ In this case, "normal" refers to all observations other than the 11 years around the downbreak. We obtain the $2.5 \%(97.5 \%)$ critical value from a t-distribution with $\min \left(G^{i}, G^{t}\right)-1$ degrees of freedom, where $G^{i}$ is the number of country clusters and $G^{t}$ is the number of time clusters.

${ }^{13}$ The authors show that robustness for two-way clustering can be achieved by calculating the variancecovariance estimates (VCE) as follows: $\hat{V}[\hat{\boldsymbol{\beta}}]=\hat{V}^{i}[\hat{\boldsymbol{\beta}}]+\hat{V}^{t}[\hat{\boldsymbol{\beta}}]-\hat{V}^{i \cap t}[\hat{\boldsymbol{\beta}}]$, where $i$ denotes countryclustered variances, $t$ denotes time-clustered variances and, in the case of a panel, $i \cap t$ indicates a White heteroskedasticity-robust variance matrix. As noted by Cameron et al. (2011), the $\hat{V}[\hat{\boldsymbol{\beta}}]$ matrix is not always positive semi-definite even though its components are, which occurs often when using fixed effects and clustering over the same units. We first within-transform the data to reduce the size of the VCE matrix and then reconstruct it via a spectral recomposition with all negative eigenvalues set to zero.
} 
Figure 3 - Growth, Output Gap and Prices
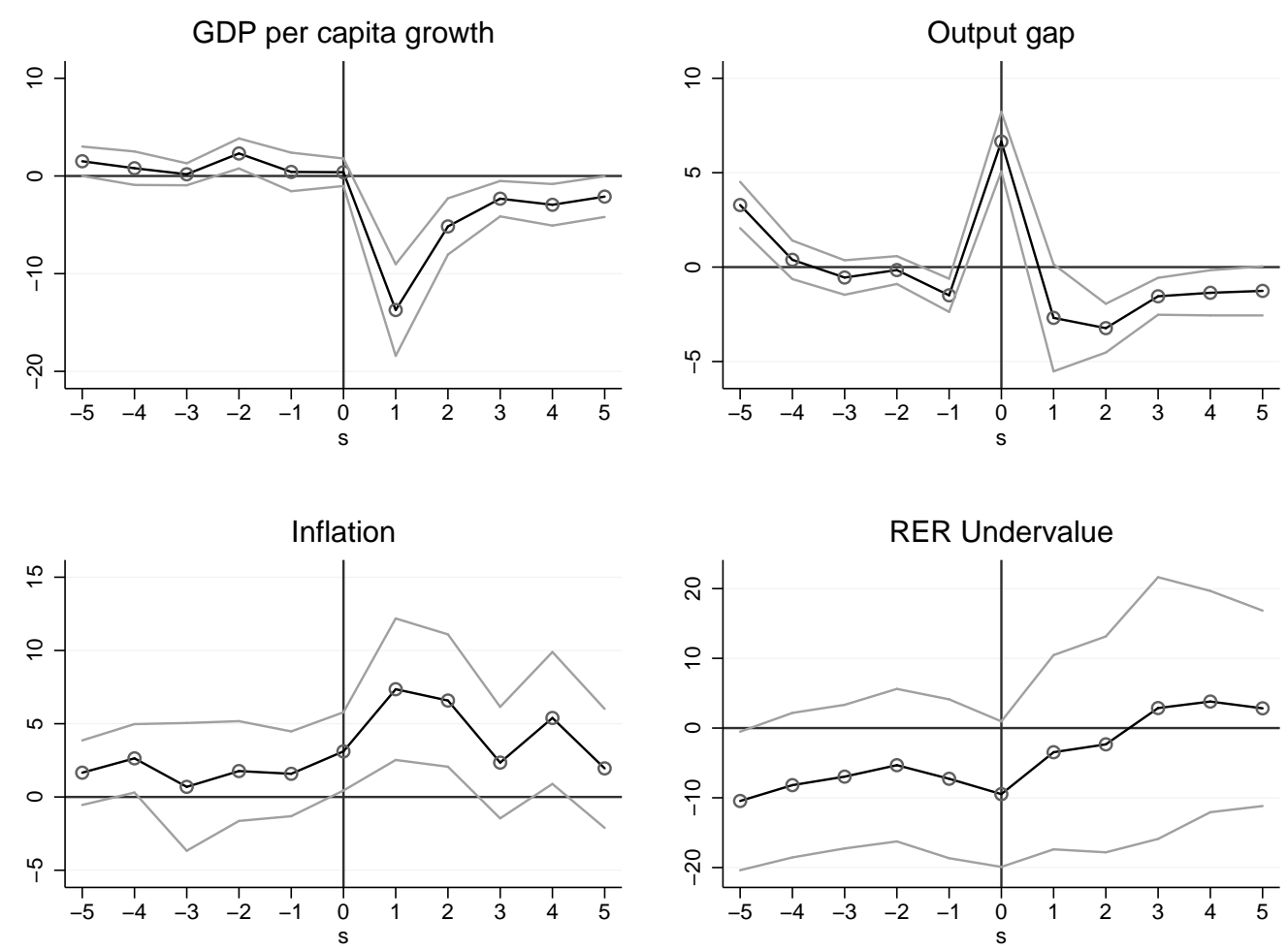

pattern is expected, it can have many causes, such as macroeconomic mismanagement or rising import prices following an exchange rate devaluation. The estimates for inflation are derived from median fixed-effects regressions with bootstrapped double-clustered standard errors ${ }^{14}$ in order to reduce the influence of large outliers caused by episodes of hyperinflation. Conversely, the real exchange rate - as measured by an undervaluation index proposed by Rodrik (2008) - is overvalued relative to normal times in the five years before the slump and when the slump hits, but then depreciates slowly towards normal levels just after the downbreak. A large strand of the empirical growth literature argues that overvaluation hurts growth prospects and may signal the advent of several types of crises. ${ }^{15}$ Figure 3 suggests that there is some currency overvaluation in the run up to crises, but the uncertainty associated with these estimates is (too) high.

What about trade and export performance? In the upper panel of Figure 4, we use two measures of trade openness to capture whether the well-accepted principle that trade openness is good for growth also holds in the reverse that less openness coincides with the occurrence of slumps. The upward trend in the $\beta_{s}$-coefficients for the de jure binary

\footnotetext{
${ }^{14}$ For the quantile regressions, we apply the results from Cameron et al. (2011) and Thompson (2011) to bootstrapping. We estimate the following VCE matrix: $\hat{V}[\hat{\boldsymbol{\beta}}]^{*}=\hat{V}^{i}[\hat{\boldsymbol{\beta}}]^{*}+\hat{V}^{t}[\hat{\boldsymbol{\beta}}]^{*}-\hat{V}^{i \cap t}[\hat{\boldsymbol{\beta}}]^{*}$, where $i$ denotes block sampling from countries, $t$ denotes block sampling from years, $i \cap t$ denotes sampling from country-years, and the superscript ${ }^{6 *}$, refers to bootstrap quantities; this is an asymptotically valid approach (Cameron et al., 2011, see in particular p. 243).

${ }^{15}$ In the "early warning signals" literature, overvaluation of the real exchange rate systematically emerges as a robust predictor of financial, currency and banking crises (Eichengreen et al., 1995; Bussière and Fratzscher, 2006; Gourinchas and Obstfeld, 2012; Frankel and Saravelos, 2012).
} 
Figure 4 - Trade \& Exports I
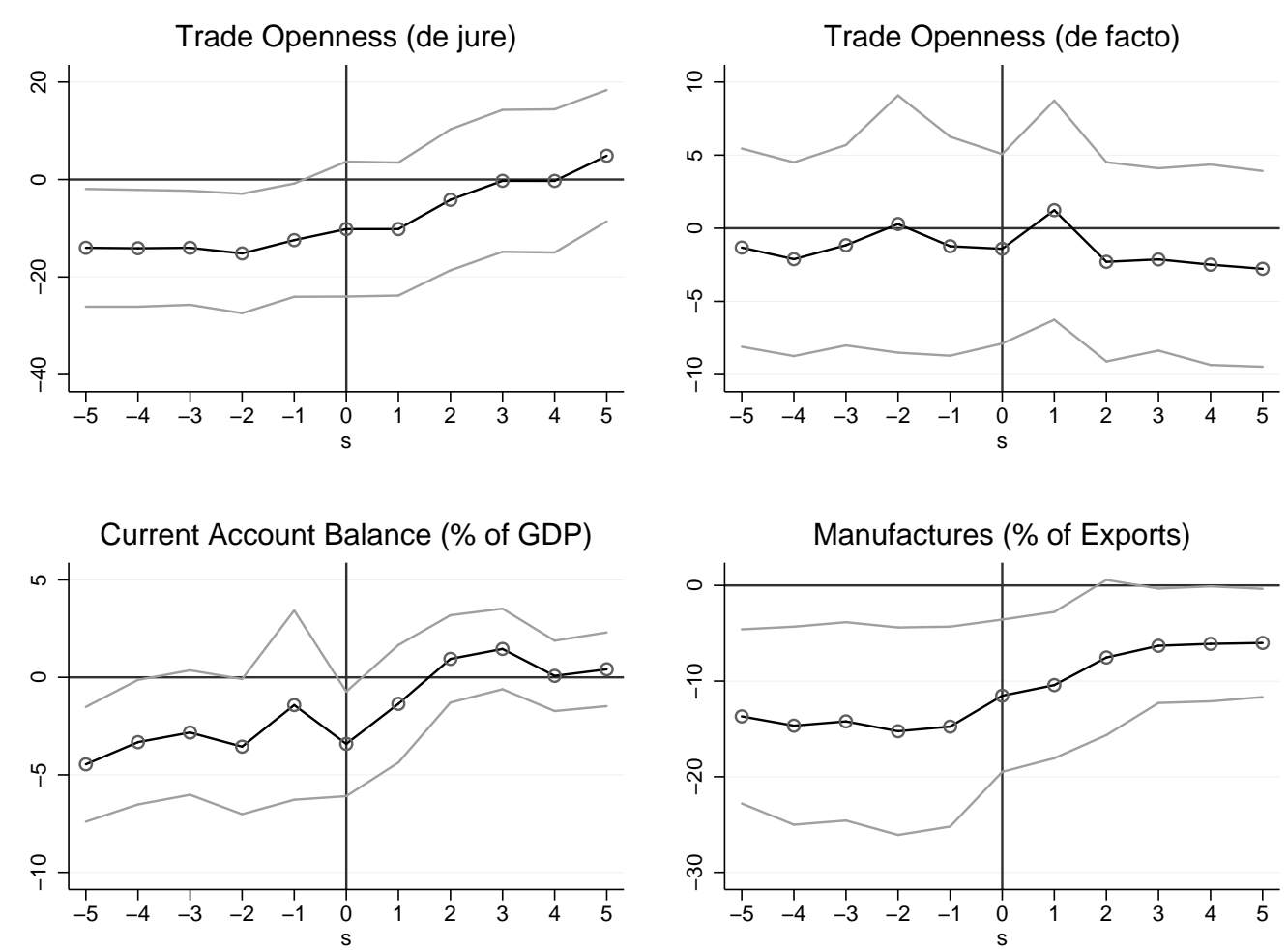

measure of trade openness proposed by Sachs and Warner (1995) ${ }^{16}$ suggests that the probability of imposing trade restrictions is higher in the run up to a slump, relative to normal times, and decreases thereafter. This effect is very significant and large, as the estimates of the linear probability model indicate that a country is 12.4 to 14.1 percentage points less likely to be open at any given year in the five years before the downbreak. Interestingly, a comparable effect is not evident when examining de facto trade openness. De facto (nominal) trade flows exhibit no systematic pattern during the 11-year window. Two other variables behave similarly to de jure openness. The current account balance is somewhat lower relative to normal times before the slump hits but then naturally improves as the relative price of imports rises and export prices decline. This trend is mirrored by the share of manufacturing exports in total exports, which is significantly lower before the slump starts but increases continuously in the five years thereafter.

Figure 5 shows how other, more structural, measures of trade performance evolve around the downbreak. A well-established empirical result is that terms of trade shocks spur output volatility and could cause growth collapses (Rodrik, 1999). We measure terms of trade shocks as the annual growth rate of the net barter terms of trade. For the slumps in our sample, terms of trade shocks do not precede the downbreak on average, but the terms of trade worsen markedly relative to normal times in the first two years of the downturn (-9\% and $-4.4 \%)$. This effect is most likely due to a depreciating currency. Next, we examine the structure of a country's export portfolio. Narrow export baskets could make countries more vulnerable to demand and supply shifts in just a few industries, while countries with more diversified export baskets may be more insulated against such

\footnotetext{
${ }^{16}$ We use the updated version of their data as presented in Wacziarg and Welch (2008).
} 
Figure 5 - Trade \& Exports II
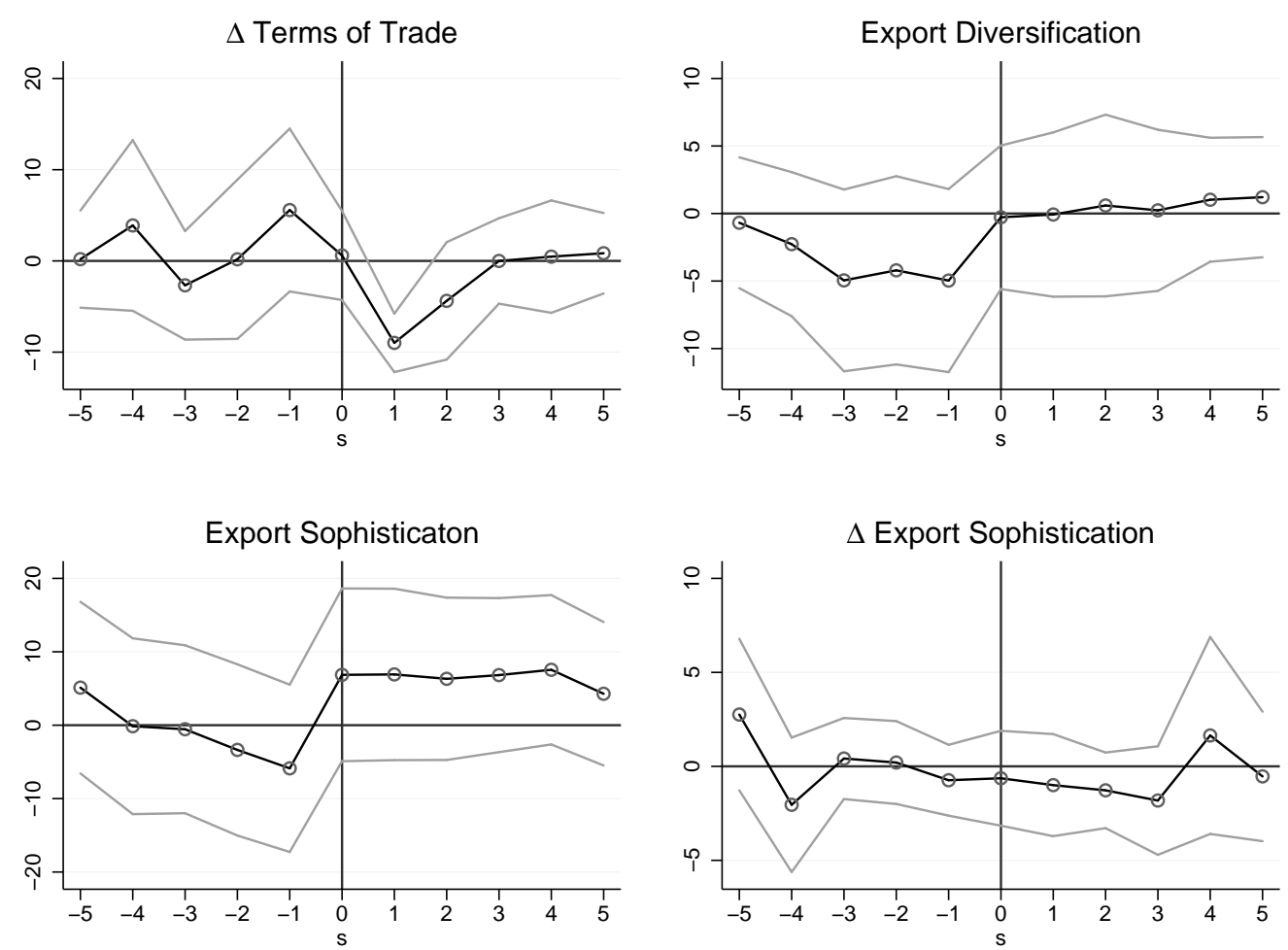

shocks. In line with this expectation, we find that the conditional expectation of export diversification - measured as one minus the Herfindahl concentration index - is lower before a slump begins and increases to normal level as it progresses. However, these differences in means are insignificant. Further, Hausmann et al. (2007) suggest that higher export sophistication (higher quality of the export basket) benefits growth directly. The lower panel of Figure 5 examines this relationship. The first graph shows the conditional expectation of the Hausmann et al. (2007) measure, which suggests that export baskets are of less quality in the two years before the break but improve relative to normal times from the year preceding the slump onwards. The second graph examines this relationship in differences. Interestingly, the improvement in export sophistication after the downbreak disappears. The relative movements in both levels and differences are not significant at conventional levels.

Figures 6 and 7 show trends in several financial indicators. A widespread conception is that financial globalization and financial development benefit growth by reducing (consumption) volatility through lowering interest rates, broadening access to credit, and better allocating resources across the domestic economy (and global economy). While this notion draws on evidence from several empirical studies (e.g. King and Levine, 1993; Beck et al., 2000), the question of causality is still unresolved and often found to run both ways or work through indirect channels, such as technology spillovers or institutions. As in the case of trade openness, we compare the findings from de jure financial openness using an indicator of capital account restrictions (Chinn and Ito, 2006) and a measure of de facto financial integration, as a country's capital account may be open but real flows are few and vice versa - for a discussion of this distinction see Kose et al. (2009). 
Three out of four indicators in Figure 6 are below their normal levels before the slump occurs. The capital account is more restricted relative to normal times before the slump occurs and restrictions increase further after the downbreak. Similarly, financial integration, measured as the sum of all foreign assets and liabilities over GDP, is depressed both before and after the downbreak. Liquid liabilities over GDP - an indicator of financial depth - are significantly lower, by about -6 to -10 percentage points, in the years before the crisis but then adjust upwards to normal levels. The upward drift in financial depth and financial integration may be due the denominator (GDP) shrinking faster than the assets and liabilities of the financial system. When examining the role of more specific financial institutions using an indicator of financial development (Deposit Money over Central Bank Assets), we find that financial development is higher before the break date and then declines during the slump. This may be in part due to an expansion of the Central Bank's balance sheet, possibly coinciding with a contraction of deposit money. However, almost none of these differences are significant at conventional levels.

Figure 6 - Finances I
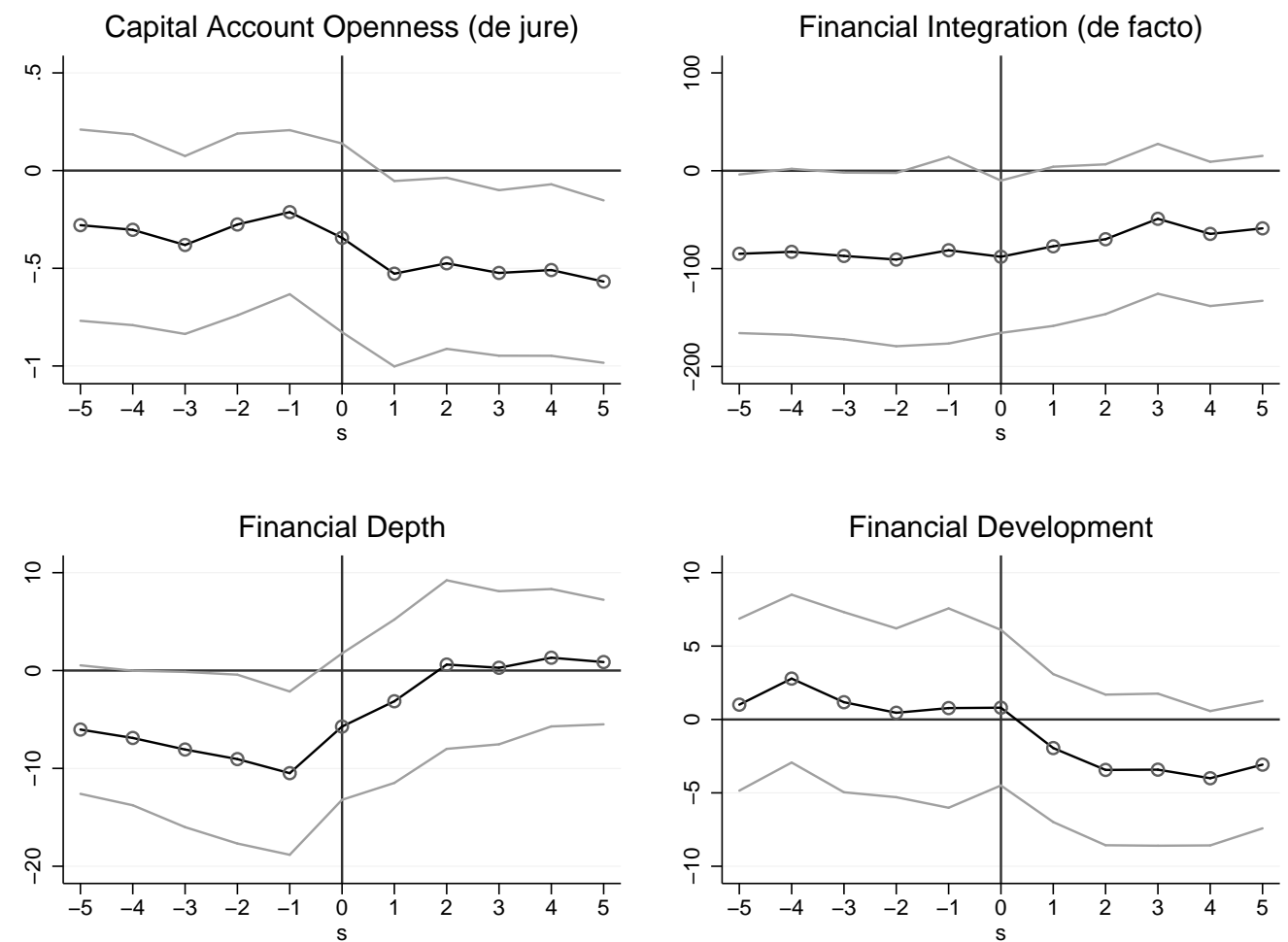

In the case of external balances the results are very clear (see Figure 7). Slumps do not appear to be debt driven. External debt liabilities are very low relative to normal times before the slump occurs, then increase by about 10 percentage points but still remain lower than in normal times. However, this variation is measured with considerable uncertainty. ${ }^{17}$ Gourinchas and Obstfeld (2012) devise a leverage ratio for countries in an empirical analogy to how leverage of firms is defined - a broader concept than just external debt. Similarly to debt levels, this measure indicates that the countries in our sample are

\footnotetext{
${ }^{17}$ There are time trends involved in the build-up of debt. Using a two-way fixed effects model shifts the curve up around zero at all event times in the 11-year window, supporting our conclusion.
} 
significantly less reliant on external financing in the 11 year window than at normal times. Not only is debt low, the stock of FDI liabilities is also about 8-10 percentage points lower throughout the 11 year period relative to normal times, suggesting that periods before and during slumps are associated with comparatively little FDI inflows (usually considered particularly desirable and stable investment flows). Taken together, these graphs suggest that most of the countries in our sample are not well integrated into global finance in the run up to a slump. This is not surprising given that rapid financial globalization and deeper financial integration of emerging markets occurs relatively late (1990s onwards). Contrary to this pattern, private credit to GDP is depressed just before the slump, much like financial depth. Hence, contractions in credit may indicate upcoming slumps.

Figure 7 - Finances II
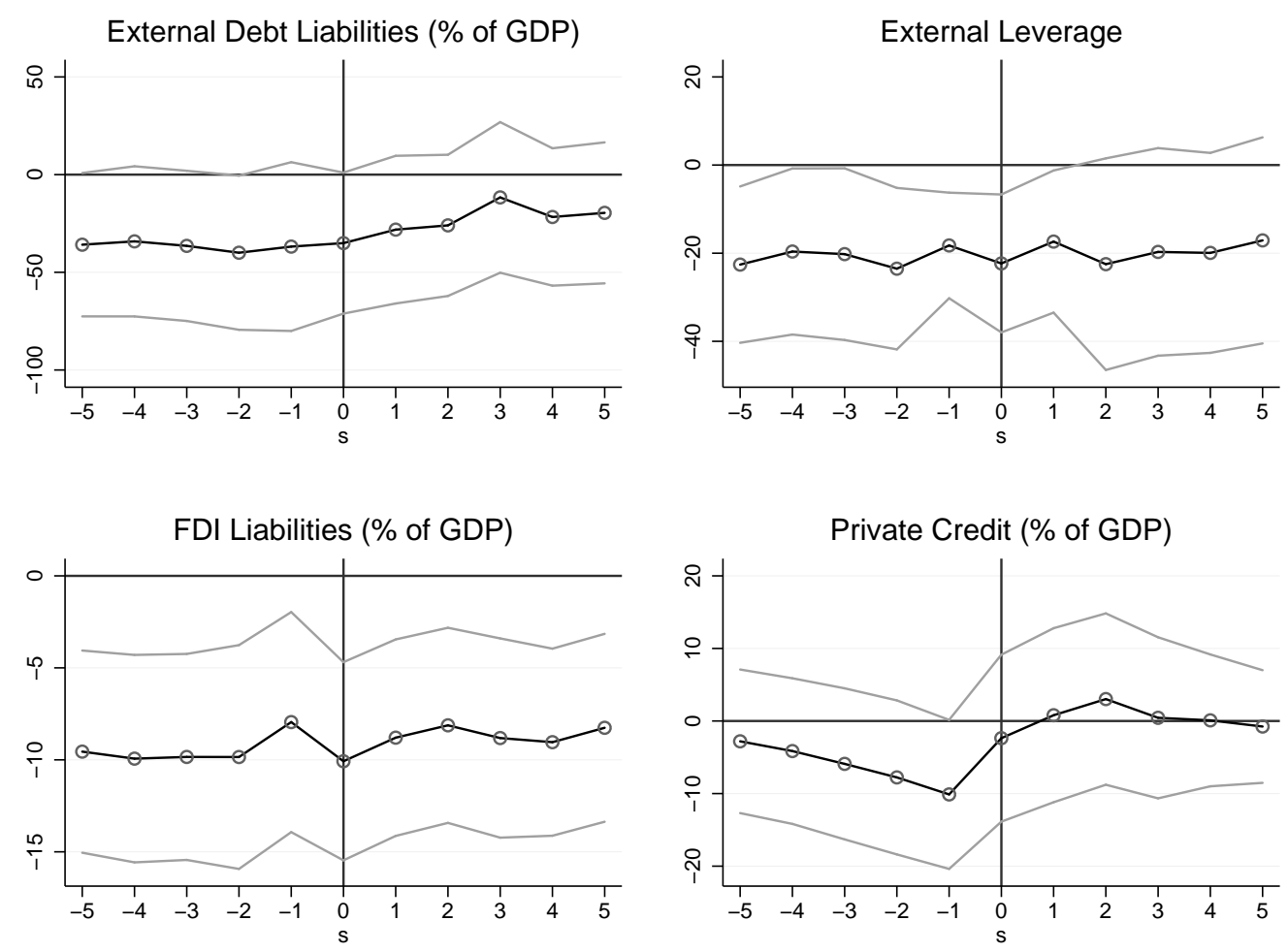

Figure 8 shows graphs describing how certain institutional and political dynamics evolve around the downbreak. In many ways, these results are the most remarkable of this section. The Polity score is much lower before a slump occurs, but increases towards normal levels thereafter. In the five years before a slump, the conditional expectation is between 2.5 and 3.1 points lower than in normal times and until the break date these differences are significant at the 5\%-level. This suggests that prior deficiencies in institutions increase vulnerability to slumps and institutions improve during/ after slumps occur. All the subcomponents of the combined Polity score, including constraints on the executive, exhibit very similar trends (not shown, available on request). Conversely, the ICRG's 6-point corruption indicator shows a moderate, yet insignificant, decrease in corruption in the first two years of a slump. The ICRG series also suffers from low coverage; it begins only in 1984 while a majority of the slumps in our sample start earlier.

The pattern of institutional reform is confirmed by the time profile of the probabilities 
Figure 8 - Institutions \& Politics
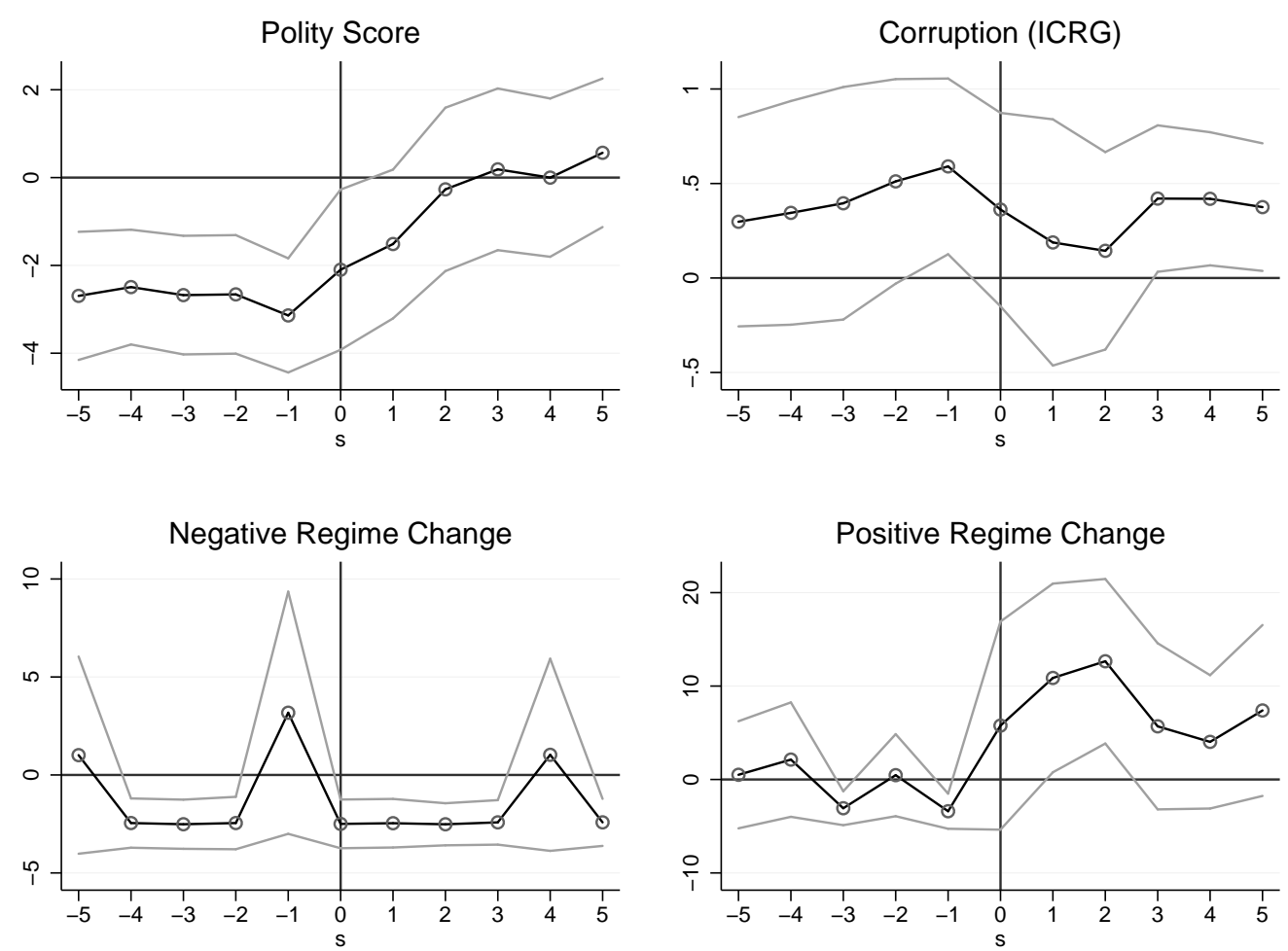

of negative or positive regime changes, measured as a minimum three-point downward or upward change in the Polity score. There is little evidence that negative regime changes precede downbreaks or systematically occur thereafter. What is very interesting, however, is an upward trend in the probability of positive regime changes from the eve of the slump onwards. In the first and second year of a slump, the probability is 10-12\% higher than in normal times. While these point estimates are individually significant, the sequence of positive estimates is even more convincing. In sum, slumps are preceded by weak institutions. However, they also present windows of opportunity as sharply negative growth creates room for political and economic reforms. A bold interpretation would be that given prior institutional deficiencies, slumps bring about a form of creative political destruction by altering power relations and increasing the pressure on governments to pursue institutional change (North et al., 2009). ${ }^{18}$

Figure 9 shows a set of complementary measures which are sometimes interpreted as the degree of open or latent social conflict challenging the conflict management capacity of a country's institutions. The picture these indicators present is mixed. Inequality, as measured by the Gini coefficient, is not significantly higher than normal before or after the downbreak. This is not too surprising. On the one hand, income inequality is a deeply rooted social phenomenon implying that we typically see few swift changes. On the other

\footnotetext{
${ }^{18}$ This is a common theme in the literature on the political economy of institutions. Weak institutions can be the cause of declining overall wealth, by providing incentives to seek rents. At the same time, declining wealth may bring about political realignments as the bargaining position of actors changes. See among many others Acemoglu et al. (2004), Acemoglu and Robinson (2006), and North et al. (2009). Greif and Laitin (2004) go even further and argue that equilibrium institutions are self-undermining if they do not continuously broaden the set of situations in which they are supported.
} 
Figure 9 - Social \& Political Conflict
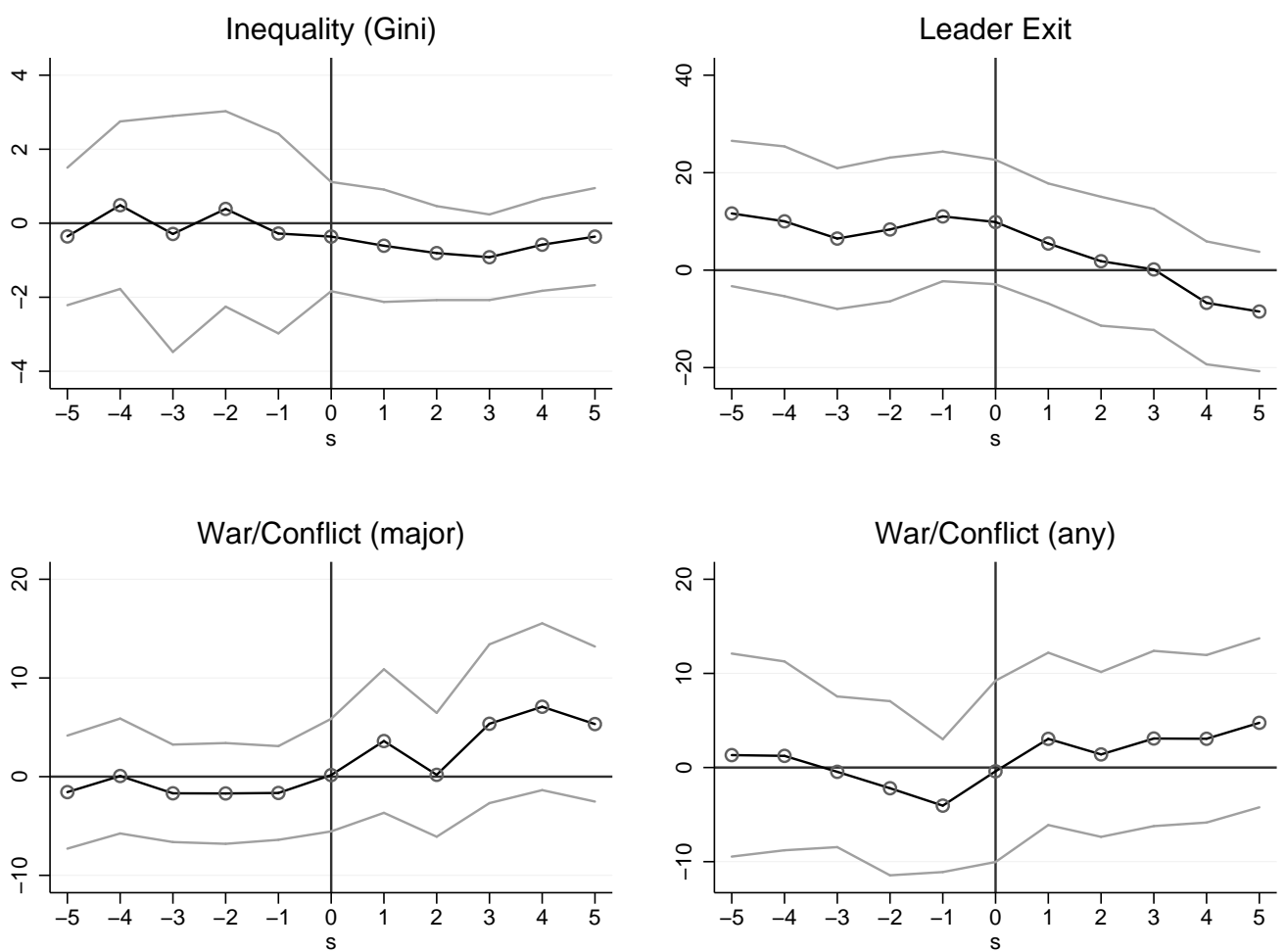

hand, even if we expect inequality to respond to crises, it is not clear which part of the income distribution will be most affected. Crises do not necessarily just hit the poor but may also have large negative effects on capital incomes and other types of income, so that "churning" under the surface can make the overall impact on the Gini ambiguous. However, this finding does not preclude that differing levels of initial inequality could be associated with the duration of declines.

Next, we examine three additional indicators of outright conflict. The variable irregular 'leader exit' measures coups d'états, assassinations, but also deaths of leaders in office and other forms of abrupt government changes that could tip an institutionally weak country into crisis (Goemans et al., 2009). Figure 9 illustrates that the probability of an irregular exit is higher relative to normal times prior to the first year of the slump, but these differences are statistically insignificant. Political turmoil is thus at best weakly linked to subsequent crises. Outright wars or major conflicts ${ }^{19}$ between state and nonstate actors are another extreme form of social conflict that could in many ways destroy the economic base of a country, cause slumps to occur, and could prolong their duration. In fact, we find wars do not coincide with slumps. The probability of war increases from the eve of the slump onwards, yet there is no indication that - on average - wars tip countries into slumps. The effect is even weaker when we use a lower threshold designed to capture low intensity conflicts ${ }^{20}$ such as ongoing civil strife and other forms of sectarian violence. There is a slight upward trend from two years after the downbreak onwards,

\footnotetext{
${ }^{19}$ Defined as any armed conflict coded as 'war' in the PRIO Armed Conflict Database; that is, any ongoing conflict with 1,000 battle related deaths in any given year.

${ }^{20}$ War/Conflict (any) is coded as unity if there are at least 25 battle related deaths in any given year.
} 
but the coefficients are both quantitatively small and statistically insignificant.

To summarize, this section outlined the characteristics of slumps and identified several factors associated with the decline phase. ${ }^{21}$ Many indicators and economic aggregates evolve in the expected manner but often represent a mix of endogenous policy responses. For example, higher inflation, a depreciating real exchange rate and a re-balancing of the current account are both testament of the strong price pressures faced by these economies but also of the necessary adjustments that ultimately help to stabilize the downturn. Other covariates behave in interesting ways around the break date. The difference between de facto trade flows and de jure openness is striking and suggests that trade restrictions play an important role for the occurrence of slumps. Additionally, several indicators of exports, financial development and financial integration either switch means around the time the slump hits or remain permanently below the levels of normal times throughout. While this exercise could certainly be extended further with more policy variables, the most interesting and unexpected finding is a switch from significantly lower quality institutions in the run up to a slump back to better scores occurring in the first two years after the downbreak. This indicates that weaker institutions precede the beginning of a slump, while the slump itself offers a window of opportunity for institutional improvements, and thus illustrates the endogenous nature of reforms.

\section{The duration of declines}

\section{Methodology}

There are two major approaches to dealing with duration data: semi-parametric Cox models and parametric models. Cox models form so-called risk sets of the subjects in the sample at the observed event times and then compute the probability of the event of interest occurring in each particular risk set. The main advantage of Cox regression is that the so-called baseline hazard can have any shape (as long as the conditional hazard is proportional). Parametric models, on the contrary, require more explicit assumptions about the shape of the baseline hazard but in turn also allow more detailed predictions.

We take a parametric approach. Parametric models can either be cast as proportional hazard $(\mathrm{PH})$ or as accelerated failure time (AFT) models. $\mathrm{PH}$ models directly begin with a log-linear specification of the hazard function. In other words, they model the instantaneous probability of an event occurring at a particular time conditional on the event not having occurred before. Proportionality then implies that the hazard function for each subject in the sample is a multiple of the baseline; that is, the baseline hazard is scaled up and down by the different realizations of the covariates. From the hazard function, we can derive the survival function which captures the cumulative probability of the event not having occurred until the observed time. The event of interest is usually defined as the 'exit' from an 'initial state'. In our case, the 'initial state' corresponds to the decline phase and 'exit' corresponds to entering the recovery phase. If a country is observed to exit the decline phase at some time, we estimate the probability of the recovery starting at that particular time (conditional on the decline phase lasting until that time). If there is no observed exit from the decline phase, then the observation is censored and only the survival probability enters the likelihood. AFT models describe the

\footnotetext{
${ }^{21}$ We do not attempt to "explain" the onset of crises in this paper. For such an analysis see the "early warning signals' literature cited in the text, but also Bluhm et al. (2012).
} 
same relationships but begin with a log-linear model of time itself. Hence, AFT models closely resemble linear regression. The hazard function and survival function are then characterized indirectly by the distribution of the error terms in the log-linear model.

All parametric models assume a certain shape of the baseline hazard. The exponential model assumes that the hazard is constant over the entire duration process. Models with a Weibull or Gompertz distribution allow for flat, monotonically increasing or monotonically decreasing hazard rates. Log-normal and log-logistic models provide a non-monotonic function that is first increasing and then decreasing. Alternatively, the generalized gamma distribution is very flexible and encompasses the exponential, Weibull and log-normal distributions but is more demanding to estimate.

We have no strong theoretical prior that the hazard function must follow a particular shape. We may expect some countries to exit rather quickly and others to take longer, but it is difficult to determine ex ante if remaining in the decline phase for very long leads to a deterioration of fundamentals and thus a decreasing hazard, or if the probability of exit is actually increasing because countries are bound to enter the recovery phase eventually.

Figure 10 - Unconditional Survival and Hazard Functions

(a) Kaplan-Meier Survival Function

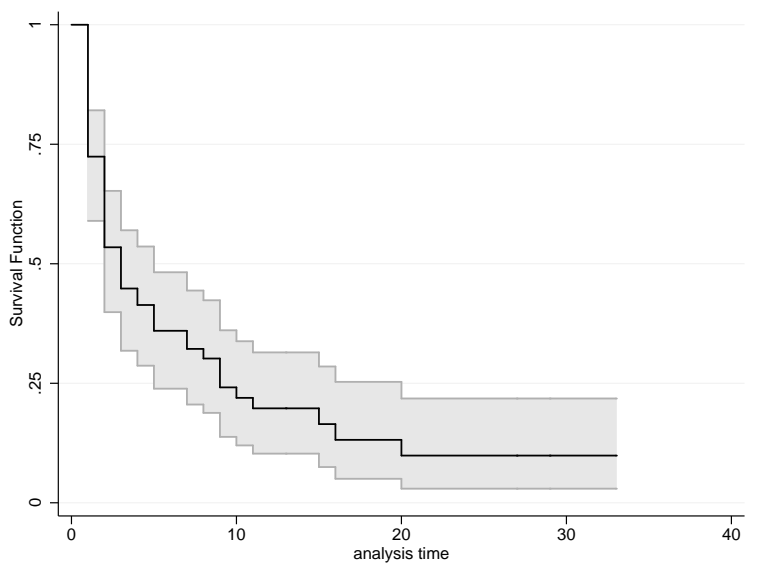

(b) Gaussian Hazard Function

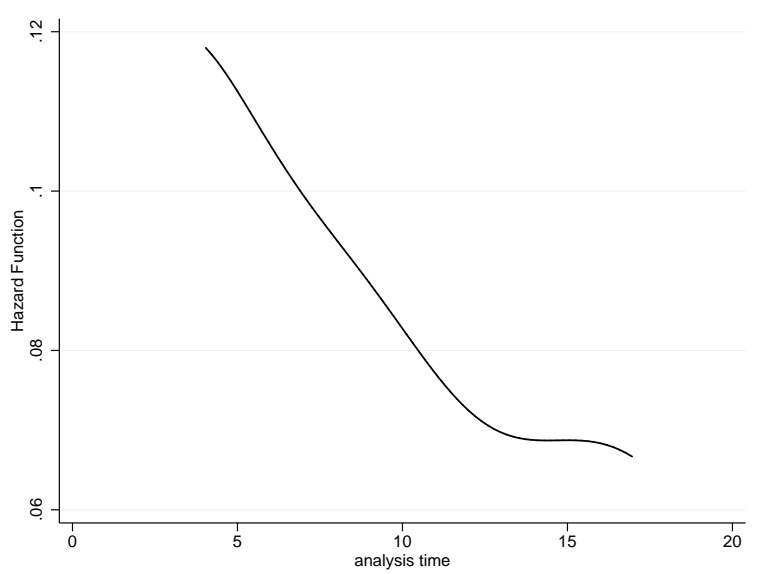

Note(s): The Kaplan-Meier survival curve is a non-parametric estimate of the probability of remaining in the decline state at each unit of analysis time. 95\% confidence intervals are shown in grey. The corresponding hazard function has been smoothed using a Gaussian kernel with boundary adjustment and bandwidth 3 .

Figure 10 shows the non-parametric Kaplan-Meier estimate of the unconditional survival function and the corresponding (smoothed) Gaussian hazard function. About $47 \%$ of the spells in our sample end after only two years of decline, but the probability of exiting the decline phase steeply and monotonically decreases over time. Nevertheless, the shape of the conditional hazard (with covariates) may be very different. We take a flexible approach by first relying on a log-normal parameterization and then testing the robustness of our preferred specification under different distributional assumptions. It is important to note that the log-normal model does not imply proportionality of the conditional hazard function. Hence, it can only be represented in the AFT metric. We provide a more detailed description of how log-normal AFT models are estimated in Appendix D.

Let analysis time be $\tilde{t}$, where $\tilde{t} \equiv t-t_{0}$ and $t_{0}=\widehat{t b}_{1}$, so that we can refer to the calendar times $t$ and $t_{0}$ when necessary. The last observed duration is $\tilde{t}_{D}=\hat{t}_{\text {min }}-\widehat{t b}_{1}$. 
We specify the following duration process in AFT form:

$$
\ln \tilde{t} \equiv \ln \left(t-t_{0}\right)=\alpha+\beta I N S_{0}+\gamma E L F+\mathbf{x}_{0}^{\prime} \boldsymbol{\xi}+\mathbf{z}_{t}^{\prime} \boldsymbol{\zeta}+\epsilon_{t}
$$

where $I N S_{0}$ is a measure of institutions fixed at $t_{0}, E L F$ is a time-invariant measure of ethnic fractionalization, $\mathbf{x}_{0}=\left(x_{0,1}, x_{0,2}, \ldots, x_{0, k}\right)$ is a $k \times 1$ vector of covariates fixed at $t_{0}$, $\mathbf{z}_{t}=\left(z_{t, 1}, z_{t, 2}, \ldots, z_{t, m}\right)$ is an $m \times 1$ vector of strictly exogenous time-varying covariates, and - for the log-normal model $-\epsilon_{t}$ is distributed $\mathcal{N}\left(0, \sigma_{\epsilon}\right)$. All parameters, including $\sigma_{\epsilon}$, are estimated with Maximum Likelihood (ML) and, as usual, we assume that censoring is independent of the duration. Our coefficients of interest are $\beta$ and $\gamma$. We suppress the country-spell index to simplify the exposition.

The estimated coefficients represent semi-elasticities of the expected duration with respect to the covariates, or elasticities if the covariate is in logs. The term 'accelerated failure time' derives from the interpretation of the implied effects. If the coefficient of the covariate is positive, then the expected duration until the event is prolonged by larger realizations of the covariate. In our case, this is equivalent to delayed exit from the decline phase (later start of the recovery). If the coefficient is negative, then the expected duration is shortened and the recovery will start earlier.

A complication of using time-varying covariates is possible feedback running from the duration to the covariates. If such feedback occurs, the estimated coefficients are biased and the usual test statistics are invalid (Lancaster, 1990; Kalbfleisch and Prentice, 2002). Joint modeling of the covariate and the duration outcomes can sometimes achieve valid inference in the presence of feedback, but with multiple endogenous regressors this quickly becomes a daunting task. In order to avoid such problems altogether, we simply take the last pre-slump value of all potentially endogenous covariates at $t_{0}$, including our measure of institutions. Hence, we close the feedback channel running from longer declines to, say, weaker institutions and rule out simultaneous causality. This is particularly important given that the previous section showed that positive institutional reforms occur during crises. In addition to the time-invariant measure of ethnic fractionalization, only the real US interest rate is assumed to be strictly exogenous.

Countries can have several recurrent slumps. This is a minor concern in our application, since only 8 of the 58 spells in our data are not the first spell for a given country. In order to account for the dependence of the parameter estimates across spells of the same country, we allow their variances to be correlated using the standard sandwich estimator of the variance-covariance matrix. As this procedure assumes that the sequence of repeated spells does not matter, we show in the robustness section that our results hold when this assumption is relaxed.

Dealing with a maximum of only 48 exits in 58 decline spells over the entire period of 1950 to 2008 requires a careful approach to model selection. The maximum sample size is statistically large enough to identify reasonably robust results, but we match these episodes with data over the almost six decades spanned by them. Including many covariates with different patterns of missing data then easily leads to sample sizes that are too small by conventional standards. Even at more moderate sample sizes, care needs to be taken to guard against overfitting. ${ }^{22}$ To arrive at a parsimonious model specification, we employ a two-step approach. First, we fit variable-by-variable regressions including only a minimal set of controls and select a smaller set of covariates for the second step

\footnotetext{
${ }^{22}$ Overfitting occurs when there are too many variables relative to the number of observations. An often used rule of thumb is to have at least five failures (exits) per variable.
} 
based on statistical significance $(p$-value $<.1)$. In other words, we select only those variables exhibiting a sufficiently strong correlation with the duration of declines. For brevity, we defer the results of the first step to Appendix E. Second, using the smaller set of covariates, we proceed with conventional model building by extending our base specification in several ways and examining its robustness. A similar approach has been used by Berg et al. (2012) who studied the duration of growth accelerations.

\section{Results}

We now directly turn to several sets of summary regressions. Our base specification always includes executive constraints as a measure of institutions, a measure of ethno-linguistic fractionalization, initial GDP per capita, the real US interest rate, and a constant. Constraints on the executive is our preferred proxy of institutional quality for two reasons. First, it is widely used in the empirical literature as a measure of institutional constraints placed on political actors and has already been linked to macroeconomic volatility (e.g. Acemoglu et al., 2003; Acemoglu and Johnson, 2005). Second, it is more conceptually rooted in the economic theory of institutions than any of the broader measures capturing wider aspects of the political regime (e.g. democracy or autocracy). Controlling for initial GDP matters, as executive constraints are correlated with the level of development (correlation: $\rho=0.43$ ), and both potentially determine the duration of declines.

For fractionalization, we use a measure from Desmet et al. (2012), who recently developed a very detailed set of estimates of ethnic cleavages. They compute the probability that two randomly chosen individuals in a country belong to different ethno-linguistic groups at 15 levels of 'the language tree'. Thus this new measure of fractionalization captures the historical nature of ethnic and linguistic differentiation into increasingly narrower groups over time. We use two variables at both extremes of the spectrum, which we could not include in Section 4 due to their time-invariant nature. ELF1 is the most aggregate level, capturing only crude distinctions such as IndoEuropean versus non-Indo European languages. ELF15 represents the most disaggregate level, differentiating among the language groups known today. Desmet et al. (2012) show that aggregate fractionalization matters more for civil conflict while the disaggregate level strongly predicts growth differentials. Hence, we use the latter as our primary measure.

The variable selection results reported in Appendix E show that the basic correlations are as expected. Stronger institutions and higher initial GDP are associated with shorter declines. Conversely, a higher degree of fractionalization and increases in the US interest rate predict longer declines. Next, we present three sets of estimations to examine if these findings are robust to the inclusion of additional variables. First, we examine how the effects of institutions and fractionalization change when other variables are added. Second, we present a set of results using our preferred specification as a base but adding other variables in thematic groups. Third, we show an expanded set of summary regressions highlighting the non-linearities involved in the effects of institutions and fractionalization on the duration of declines - a feature that has received too little attention in the empirical literature so far.

Table 2 reports the first set of summary regressions. The table is organized as follows. We enter each variable that passed the variable selection process separately into the specification in order to examine how its presence changes the coefficients of institutions and fractionalization. All variables, except de facto trade openness, enter with the expected sign. The broad patterns are very interesting. Above all, the effect of 


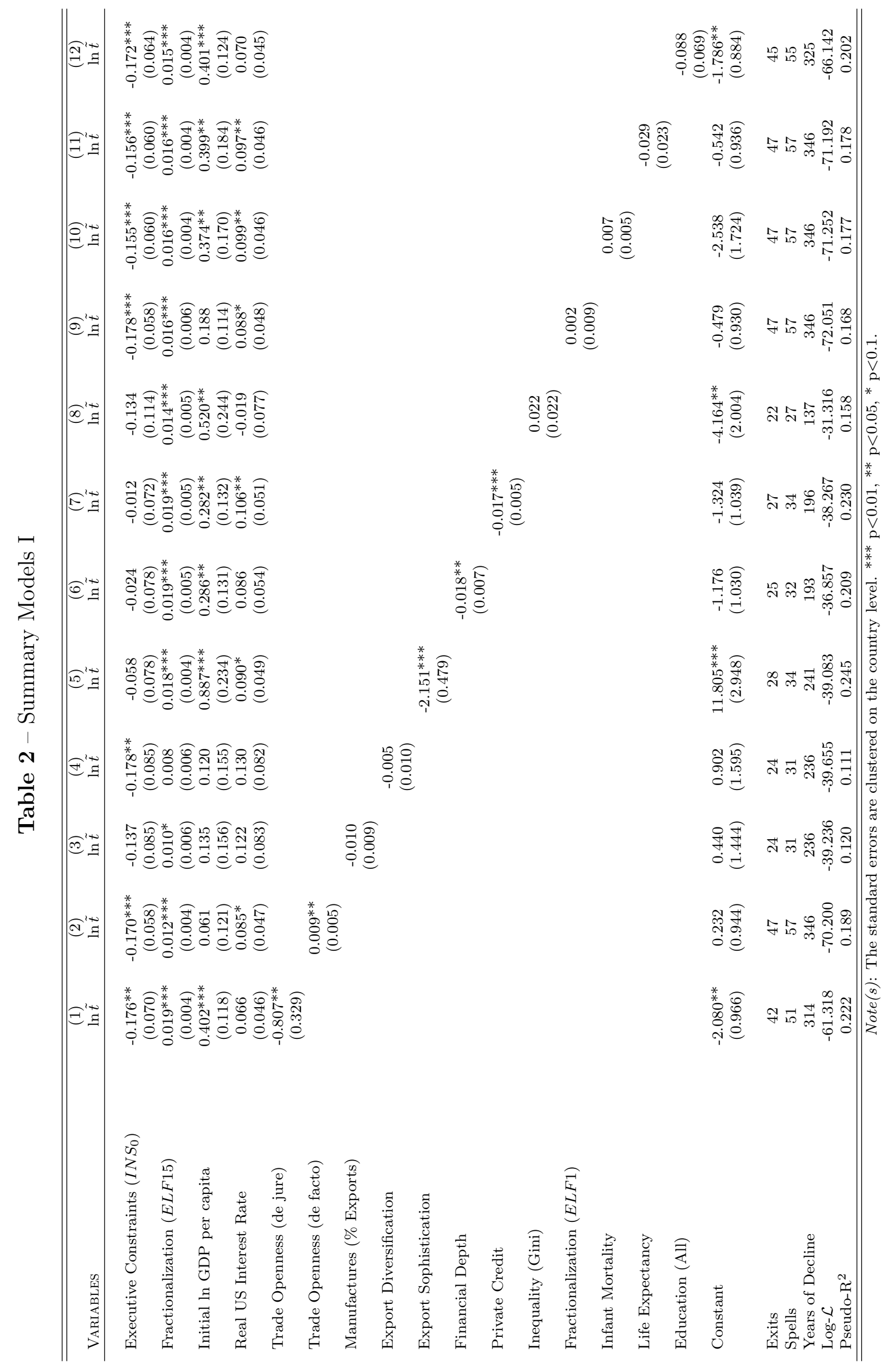


fractionalization is extremely robust in all but one model ${ }^{23}$ and varies only within a narrow band. A one percentage point increase in fractionalization is estimated to prolong the decline phase by about 1-2\%. Further, the coefficient of executive constraints is significant at the $5 \%$ or $1 \%$-level in a majority of the regressions and has a stable negative sign throughout. Most models imply that a one point improvement in executive constraints leads to $13-18 \%$ reduction in the duration of the decline phase. However, the coefficient becomes small when we control for export sophistication, private credit to GDP, and financial depth - in each case, we lose roughly half the sample. Due to the smaller sample size, the standard error of executive constraints also widens substantially when controlling for the share of manufactures in total exports or inequality, but the coefficient remains similar. In the case of export sophistication and the two financial variables, two factors could be driving the changes in the coefficient on institutions: sample selection and endogeneity/ multicollinearity. We find that in all three cases, sample selection is only partially responsible ${ }^{24}$ but that there are strong grounds to suspect that both the ability to produce more sophisticated exports and sustain a complex financial system must first be preceded by well-developed institutions (correlation: $\rho \in[0.56 ; 0.62]$ ). In fact, we can characterize these complex features of modern economies as outcomes of institutional development and do not interpret this as a lack of robustness (e.g., see Acemoglu et al., 2003, for a similar point and additional evidence).

Interestingly, the coefficient of the log of GDP per capita just before the slump consistently has a positive sign once we control for our covariates of interest, implying the counterintuitive result that higher initial GDP prolongs declines. Yet, as the singlevariable models in Table 10 of the Appendix show, higher initial GDP is unconditionally associated with shorter declines but insignificantly so $(p$-value $=0.39)$ and initial GDP adds little explanatory power to the constant-only model. In Table 2 and all subsequent models, the coefficients and standard errors of initial GDP remain very unstable. The implied elasticities of the duration with respect to initial GDP range from 0.06 to 0.89 , depending on the sample size and the controls. While we do not exclude initial GDP from our models in order to not spuriously assign its effect to institutions, we only treat it as a control variable and do not attempt to give its effect a causal interpretation.

Several of the variables that passed the selection step have effects that are not robust in a multivariate setting. The coefficients of the share of manufactured exports, export diversification, and inequality point in the expected direction but are insignificant by a large margin. The results also help to determine which of the two measures of fractionalization should be preferred in our context. Complementing the results of Desmet et al. (2012), we find that when controlling for both the disaggregate and aggregate measures of fractionalization at the same time, the disaggregate measure (ELF15) captures more of the relevant variation in the duration of declines. All of the 'other determinants', that is, life expectancy, infant mortality and years of schooling, are insignificant in the expanded models and have hardly any effect on the partial effects of institutions or fractionalization.

Table 3 takes a different approach to addressing the issue of omitted variables. Instead of adding variables one-by-one, we now add groups of variables measuring similar yet

\footnotetext{
${ }^{23}$ When also controlling for export diversification, we lose nearly half the sample and the coefficient of ELF15 becomes small and insignificant. However, the sign remains stable and the standard error increases only marginally.

${ }^{24}$ The size and significance of executive constraints weakens somewhat when the estimation sample is restricted to be the same as if either of these three variables were included.
} 
Table 3 - Summary Models II

\begin{tabular}{|c|c|c|c|c|c|c|}
\hline VARIABLES & $\begin{array}{l}(1) \\
\ln \tilde{t}\end{array}$ & $\begin{array}{l}(2) \\
\ln \tilde{t}\end{array}$ & $\begin{array}{l}(3) \\
\ln \tilde{t}\end{array}$ & $\begin{array}{l}(4) \\
\ln \tilde{t}\end{array}$ & $\begin{array}{l}(5) \\
\ln \tilde{t}\end{array}$ & $\begin{array}{l}(6) \\
\ln \tilde{t}\end{array}$ \\
\hline Executive Constraints $\left(I N S_{0}\right)$ & $\begin{array}{c}-0.181 * * * \\
(0.066)\end{array}$ & $\begin{array}{l}-0.149 \\
(0.102)\end{array}$ & $\begin{array}{l}-0.007 \\
(0.075)\end{array}$ & $\begin{array}{c}-0.172^{* * *} \\
(0.063)\end{array}$ & $\begin{array}{c}-0.111^{*} \\
(0.064)\end{array}$ & $\begin{array}{c}-0.178 * * * \\
(0.058)\end{array}$ \\
\hline Fractionalization $(E L F 15)$ & $\begin{array}{c}0.015^{* * *} \\
(0.004)\end{array}$ & $\begin{array}{c}0.016^{* * *} \\
(0.006)\end{array}$ & $\begin{array}{c}0.019^{* * *} \\
(0.005)\end{array}$ & $\begin{array}{c}0.016^{* * *} \\
(0.004)\end{array}$ & $\begin{array}{c}0.014^{* * *} \\
(0.005)\end{array}$ & $\begin{array}{c}0.016^{* * *} \\
(0.004)\end{array}$ \\
\hline Initial ln GDP per capita & $\begin{array}{c}0.282^{* *} \\
(0.125)\end{array}$ & $\begin{array}{c}1.014^{* * *} \\
(0.290)\end{array}$ & $\begin{array}{c}0.293^{* *} \\
(0.132)\end{array}$ & $\begin{array}{c}0.559^{* * *} \\
(0.171)\end{array}$ & $\begin{array}{c}0.459^{* * *} \\
(0.164)\end{array}$ & $\begin{array}{l}0.197^{*} \\
(0.106)\end{array}$ \\
\hline Real US Interest Rate & $\begin{array}{c}0.063 \\
(0.044)\end{array}$ & $\begin{array}{c}0.065 \\
(0.073)\end{array}$ & $\begin{array}{l}0.098^{*} \\
(0.054)\end{array}$ & $\begin{array}{l}0.081^{*} \\
(0.044)\end{array}$ & $\begin{array}{l}0.074^{*} \\
(0.042)\end{array}$ & $\begin{array}{l}0.087^{*} \\
(0.048)\end{array}$ \\
\hline Trade Openness (de jure) & $\begin{array}{c}-0.772^{* *} \\
(0.312)\end{array}$ & & & & & \\
\hline Trade Openness (de facto) & $\begin{array}{c}0.010^{* *} \\
(0.005)\end{array}$ & & & & & \\
\hline Manufactures (\% Exports) & & $\begin{array}{l}-0.007 \\
(0.010)\end{array}$ & & & & \\
\hline Export Diversification & & $\begin{array}{l}-0.003 \\
(0.012)\end{array}$ & & & & \\
\hline Export Sophistication & & $\begin{array}{c}-1.559^{* *} \\
(0.777)\end{array}$ & & & & \\
\hline Financial Depth & & & $\begin{array}{l}-0.007 \\
(0.013)\end{array}$ & & & \\
\hline Private Credit & & & $\begin{array}{l}-0.011 \\
(0.008)\end{array}$ & & & \\
\hline Infant Mortality & & & & $\begin{array}{c}0.003 \\
(0.009)\end{array}$ & & \\
\hline Life Expectancy & & & & $\begin{array}{l}-0.020 \\
(0.038)\end{array}$ & & \\
\hline Education (All) & & & & $\begin{array}{l}-0.026 \\
(0.074)\end{array}$ & & \\
\hline Constant & $\begin{array}{l}-1.411 \\
(0.989)\end{array}$ & $\begin{array}{c}6.637 \\
(4.802)\end{array}$ & $\begin{array}{l}-1.346 \\
(1.035)\end{array}$ & $\begin{array}{l}-2.426 \\
(2.633)\end{array}$ & $\begin{array}{c}-3.346^{* *} \\
(1.401)\end{array}$ & $\begin{array}{l}-0.553 \\
(0.868)\end{array}$ \\
\hline Region FE & $\mathrm{NO}$ & $\mathrm{NO}$ & $\mathrm{NO}$ & $\mathrm{NO}$ & YES & $\mathrm{NO}$ \\
\hline Exits & 42 & 18 & 25 & 45 & 47 & 47 \\
\hline Spells & 51 & 22 & 32 & 55 & 57 & 57 \\
\hline Years of Decline & 314 & 166 & 193 & 325 & 346 & 346 \\
\hline $\log -\mathcal{L}$ & -59.259 & -22.668 & -36.422 & -65.321 & -63.827 & -72.090 \\
\hline Pseudo- $\mathrm{R}^{2}$ & 0.248 & 0.277 & 0.218 & 0.211 & 0.263 & 0.168 \\
\hline
\end{tabular}

different aspects of a certain theme, such as trade or finance. Most of the previous results are confirmed, but Table 3 also introduces a few refinements. First and foremost, the effect of ethno-linguistic fractionalization remains very robust. Second, interesting patterns emerge for the three groups of macroeconomic variables. Model (1) shows that de jure trade openness still holds substantial explanatory power over the expected duration and de facto openness continues to have a significant and positive effect, yet both of these covariates have little effect on the coefficients and the standard errors of institutions and fractionalization. Model (2) highlights that the coefficients of executive constraints and fractionalization are actually robust to the inclusion of export sophistication once the share of manufactured exports and the degree of export diversification are also included. Only the standard error of executive constraints increases substantially due to the smaller sample size. For the financial variables, model (3) reveals that including private credit and financial depth still reduces the coefficient of executive constraints substantially. However, the partial effects of these variables are not very robust and provide no evidence in favor of retaining these variables in the model. ${ }^{25}$ Model (4) confirms that neither life expectancy,

\footnotetext{
${ }^{25}$ This also applies to many other models where more controls are used in addition to one of the financial measures.
} 
infant mortality, or schooling have robust effects on the expected duration.

We take a different approach to addressing the issue of omitted variables in model (5) by including region dummies to account for regionally shared heterogeneity that is otherwise not captured by the observed covariates. Both the coefficients and standard errors of institutions and fractionalization are within the usual range, providing further support for the assertion that the effect of institutions is reasonably robust. Model (6) in the last column is our preferred and most parsimonious specification. This model captures most of the effects we are interested in and is estimated using nearly all available observations. Taken together, these models show that the effect of fractionalization is very robust and the effect of institutions is only strongly affected by the financial depth and credit - two measures that we consider to be observed institutional outcomes.

Figure 11 - Predicted survival functions

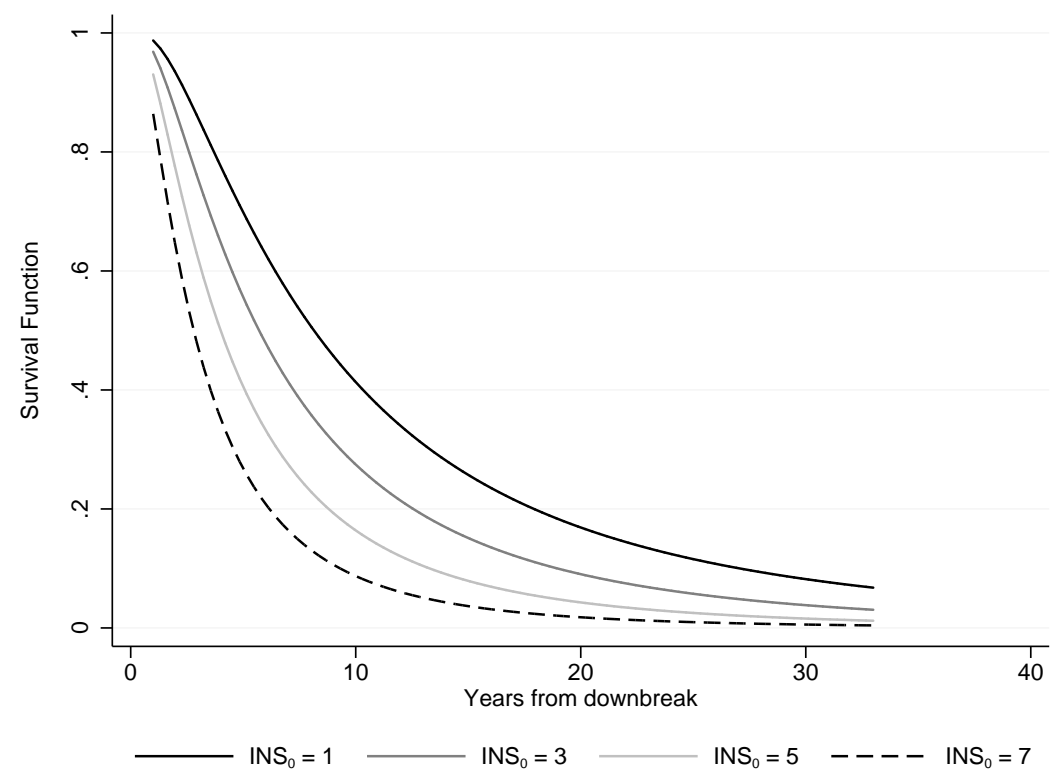

Are the effects of institutions economically meaningful? Figure 11 examines this point by plotting the survival functions predicted by our preferred specification over four different values of executive constraints (while keeping all other variables at their sample mean). As is readily observed, the effect of institutions on the expected duration is very large but plausible. In the log-normal model, the estimates of mean and median duration are equivalent and can be easily estimated by the exponentiated linear prediction. ${ }^{26}$ Conditional on having entered a slump, a country with the lowest score on the executive constraints measure is expected to decline for about 9.1 years, while a country with the highest score is expected to decline only for about 3.1 years. The mean of executive constraints in the estimation sample is about 2.4, implying a duration of 7.1 years.

As a last set of summary results, Table 4 reproduces Table 3 with one important change. Instead of imposing that institutions and fractionalization have a linearly additive effect on the expected duration of declines, we now allow for an interaction effect between the two. The rationale for this is simple. Given a political economy in which (latent) social conflict challenges the ability of political actors to take coordinated action, stronger institutions may help to overcome this negative effect. However, countries with a high

\footnotetext{
${ }^{26}$ This is a special property of the log-normal model, due to the symmetry of the error distribution.
} 
degree of fractionalization may require particularly strong institutions just to compensate. Likewise, countries with much greater degree of ethno-linguistic homogeneity may make do with less developed institutions to achieve a similar degree of social coordination. This hypothesis is a less restrictive variant of the idea that there is a multiplicative effect between social conflict and institutions in response to external shocks (Rodrik, 1999). ${ }^{27}$

Table 4 - Summary Models III

\begin{tabular}{|c|c|c|c|c|c|c|}
\hline VARIABLES & $\begin{array}{l}(1) \\
\ln \tilde{t}\end{array}$ & $\begin{array}{l}(2) \\
\ln \tilde{t}\end{array}$ & $\begin{array}{l}(3) \\
\ln \tilde{t}\end{array}$ & $\begin{array}{l}(4) \\
\ln \tilde{t}\end{array}$ & $\begin{array}{l}(5) \\
\ln \tilde{t}\end{array}$ & $\begin{array}{l}(6) \\
\ln \tilde{t}\end{array}$ \\
\hline Executive Constraints $\left(\widetilde{I N S_{0}}\right)$ & $\begin{array}{c}-0.366^{* * *} \\
(0.098)\end{array}$ & $\begin{array}{l}-0.137 \\
(0.126)\end{array}$ & $\begin{array}{l}-0.091 \\
(0.101)\end{array}$ & $\begin{array}{c}-0.280^{* * *} \\
(0.090)\end{array}$ & $\begin{array}{c}-0.217^{* *} \\
(0.087)\end{array}$ & $\begin{array}{c}-0.288^{* * *} \\
(0.080)\end{array}$ \\
\hline Fractionalization $(\widehat{E L F 15})$ & $\begin{array}{c}0.016^{* * *} \\
(0.004)\end{array}$ & $\begin{array}{c}0.016^{* * *} \\
(0.006)\end{array}$ & $\begin{array}{c}0.019^{* * * *} \\
(0.004)\end{array}$ & $\begin{array}{c}0.017^{* * *} \\
(0.004)\end{array}$ & $\begin{array}{c}0.017^{* * * *} \\
(0.004)\end{array}$ & $\begin{array}{c}0.018^{* * *} \\
(0.004)\end{array}$ \\
\hline$\widetilde{I N S_{0}} \times \widehat{E L F 15}$ & $\begin{array}{c}-0.005^{* * *} \\
(0.002)\end{array}$ & $\begin{array}{c}0.000 \\
(0.002)\end{array}$ & $\begin{array}{l}-0.003 \\
(0.002)\end{array}$ & $\begin{array}{c}-0.004 * * \\
(0.002)\end{array}$ & $\begin{array}{c}-0.003^{* *} \\
(0.001)\end{array}$ & $\begin{array}{c}-0.004 * * * \\
(0.001)\end{array}$ \\
\hline Initial ln GDP per capita & $\begin{array}{c}0.275^{* *} \\
(0.123)\end{array}$ & $\begin{array}{c}1.007 * * * \\
(0.293)\end{array}$ & $\begin{array}{l}0.238^{*} \\
(0.135)\end{array}$ & $\begin{array}{c}0.533^{* * *} \\
(0.175)\end{array}$ & $\begin{array}{c}0.439 * * * \\
(0.163)\end{array}$ & $\begin{array}{l}0.198^{*} \\
(0.106)\end{array}$ \\
\hline Real US Interest Rate & $\begin{array}{c}0.068 \\
(0.042)\end{array}$ & $\begin{array}{c}0.064 \\
(0.072)\end{array}$ & $\begin{array}{l}0.100^{*} \\
(0.054)\end{array}$ & $\begin{array}{l}0.084^{*} \\
(0.043)\end{array}$ & $\begin{array}{l}0.076^{*} \\
(0.042)\end{array}$ & $\begin{array}{c}0.098^{* *} \\
(0.047)\end{array}$ \\
\hline Trade Openness (de jure) & $\begin{array}{c}-0.690^{* *} \\
(0.298)\end{array}$ & & & & & \\
\hline Trade Openness (de facto) & $\begin{array}{c}0.015^{* * *} \\
(0.005)\end{array}$ & & & & & \\
\hline Manufactures (\% Exports) & & $\begin{array}{l}-0.008 \\
(0.012)\end{array}$ & & & & \\
\hline Export Diversification & & $\begin{array}{l}-0.004 \\
(0.011)\end{array}$ & & & & \\
\hline Export Sophistication & & $\begin{array}{l}-1.503^{*} \\
(0.784)\end{array}$ & & & & \\
\hline Private Credit & & & $\begin{array}{l}-0.008 \\
(0.009)\end{array}$ & & & \\
\hline Financial Depth & & & $\begin{array}{l}-0.008 \\
(0.011)\end{array}$ & & & \\
\hline Infant Mortality & & & & $\begin{array}{c}0.001 \\
(0.007)\end{array}$ & & \\
\hline Life Expectancy & & & & $\begin{array}{l}-0.020 \\
(0.030)\end{array}$ & & \\
\hline Education (All) & & & & $\begin{array}{l}-0.045 \\
(0.070)\end{array}$ & & \\
\hline Constant & $\begin{array}{l}-1.122 \\
(0.910)\end{array}$ & $\begin{array}{c}6.940 \\
(4.896)\end{array}$ & $\begin{array}{c}0.213 \\
(1.247)\end{array}$ & $\begin{array}{l}-1.425 \\
(2.066)\end{array}$ & $\begin{array}{c}-2.552^{*} \\
(1.362)\end{array}$ & $\begin{array}{c}0.025 \\
(0.872)\end{array}$ \\
\hline Region FE & $\mathrm{NO}$ & $\mathrm{NO}$ & NO & $\mathrm{NO}$ & YES & $\mathrm{NO}$ \\
\hline Exits & 42 & 18 & 25 & 45 & 47 & 47 \\
\hline Spells & 51 & 22 & 32 & 55 & 57 & 57 \\
\hline Years of Decline & 314 & 166 & 193 & 325 & 346 & 346 \\
\hline $\log -\mathcal{L}$ & -54.001 & -22.648 & -35.514 & -62.746 & -61.681 & -69.540 \\
\hline Pseudo- $R^{2}$ & 0.315 & 0.278 & 0.238 & 0.243 & 0.288 & 0.197 \\
\hline
\end{tabular}

In order to ease the interpretation, we subtract the sample average of the institutions and fractionalization variables from their observed values before estimating each model. We denote the demeaned variables by $\widetilde{I N S_{0}}$ and $\widetilde{E L F 15}$. This has the following effect. If either one of the two variables is at its mean, then the interaction term is zero and the only relevant coefficient is the non-interacted variant. As a result, the coefficient of the executive constraints variable directly measures the effect of institutions at the average level of fractionalization, and vice versa. For values other than the mean, the coefficient on the interaction term needs to be taken into account.

\footnotetext{
${ }^{27}$ Rodrik (1999) shows that such a multiplicative effect exists when looking at growth differentials, but does not include the base categories, which very different to a non-linear interaction as we suggest.
} 
Table 4 shows that there is considerable evidence of an interaction effect. In the same models where we find a robust effect of institutions, we also find a significant interaction effect between executive constraints and ethno-linguistic fractionalization. In most specifications, the partial effect of one variable at the mean of the other is at least as significant as in the models without an interaction effect. The interaction term is negative and significant at the 1\%-level in all versions but models (2) and (3). In model (2) there is simply not enough data to estimate this effect, whereas in model (3) the sign and size of the interaction coefficient is actually very similar to other estimations. Since our preferred specification is nested in model (6), testing the null that the interaction term is zero is equivalent to a test that this model fits the data better. A likelihood ratio test also prefers the interaction model and the pseudo- $\mathrm{R}^{2}$ improves from 0.168 to 0.197 .

Figure 12 - Partial Effects in Interaction Model

(a) Fractionalization $(E L F 15)$

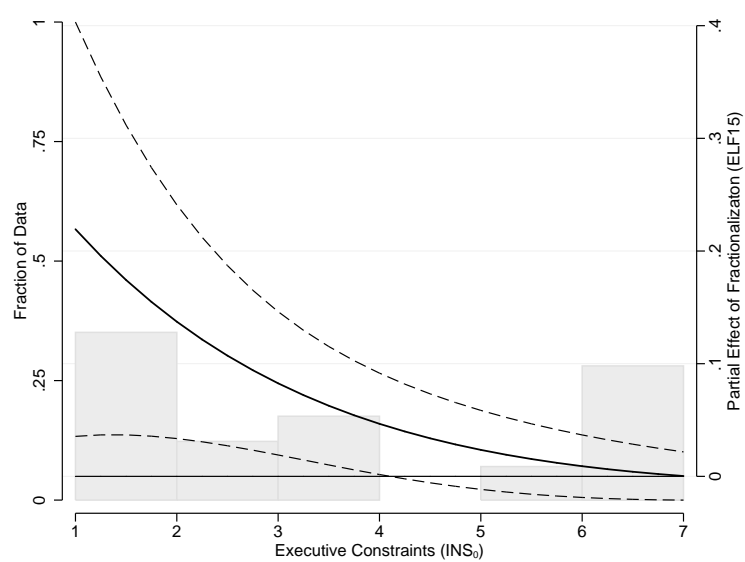

(b) Executive Constraints $\left(I N S_{0}\right)$

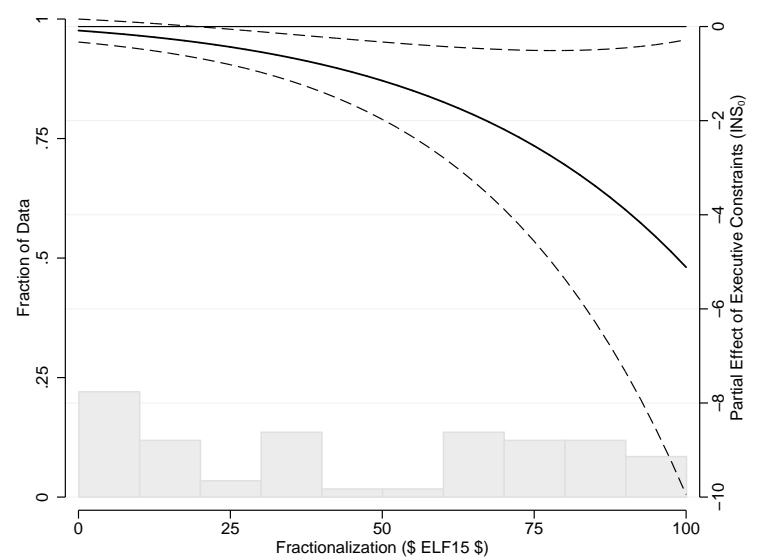

Note(s): The partial effects are based on the preferred specification in Table 4 and are computed over the entire range of the variable on the $\mathrm{x}$-axis while keeping all other regressors at their mean.

Figure 12 illustrates that the effects estimated in the interaction model are economically and statistically significant. It plots the predicted semi-elasticities of the expected duration with respect to one variable of the interaction term over representative values of the other, including a $95 \%$ confidence interval. Three points stand out: 1) the effect of executive constrains clearly depends on fractionalization (and vice versa), 2) both partial effects are significant over most of the distribution, and 3) both partial effects consistently have the expected sign. The sampling distribution of executive constraints covers the entire theoretical range (scores 1 to 7 ) and ethno-linguistic fractionalization ranges from near perfect homogeneity (0.07) to near perfect fractionalization (96). The model predictions now cover a wider range of the observed data. At the average score of executive constraints, a country with the highest (lowest) degree of ethnic heterogeneity is expected to decline for about 12.6 years (2.1 years). Hence, it would be difficult to understand the effects of institutions without considering fractionalization. Stronger institutions also have the potential to overcome the adverse effects of high levels of ethnic fractionalization. At the $75^{\text {th }}$ percentile of ethnic heterogeneity $(E L F 15=89.7)$, a country with the highest (lowest) score of executive constraints is expected to decline for about 1.8 years (18.3 years). Interestingly, the model suggests that the duration prolonging effect of fractionalization is relatively small at high levels of executive constraints $\left(I N S_{0} \in[6 ; 7]\right)$. 


\section{Robustness}

We briefly illustrate that our main conclusions are unaffected by the choice of the baseline hazard, presence of unobserved heterogeneity, exclusion of influential groups of observations, and different ways of accounting for recurrent spells. For this purpose, we run a battery of statistical tests and discuss how the choice of hazard shape relates to the time process implied by the different models.

Table 5 tackles the issues of choice of functional form and model selection. To aid a direct comparison, we report our preferred specification in the first column and then show estimates of the same model using with five different hazard functions. Model (2) uses a log-logistic hazard instead of the log-normal shape, but the parameter estimates do not change much. This is not too surprising. The log-logistic distribution is very similar to the log-normal, in that it offers a non-monotonic shape that is either first increasing and then decreasing or monotonically decreasing throughout. This model has an additional parameter $(\gamma)$ indicating which is the case. The estimated shape parameter $(\ln \gamma)$ is negative, implying that the hazard is first increasing then decreasing just as in the log-normal model. The log-likelihood is close to that of model (1) but not better, indicating a similar or, at best, minimally worse fit.

Table 5 - Robustness: functional form

\begin{tabular}{|c|c|c|c|c|c|c|}
\hline VARIABLES & $\begin{array}{c}(1) \\
\text { Log-normal } \\
\ln \tilde{t}\end{array}$ & $\begin{array}{c}(2) \\
\text { Log-logistic } \\
\ln \tilde{t}\end{array}$ & $\begin{array}{c}(3) \\
\text { Exponential } \\
\ln \tilde{t}\end{array}$ & $\begin{array}{c}(4) \\
\text { Weibull } \\
\ln \tilde{t}\end{array}$ & $\begin{array}{c}(5) \\
\text { Gompertz } \\
\ln \tilde{t}\end{array}$ & $\begin{array}{c}(6) \\
\mathrm{Cox} \mathrm{PH} \\
\ln \tilde{t}\end{array}$ \\
\hline & \multicolumn{2}{|c|}{ Coefficients } & \multicolumn{4}{|c|}{ Hazard Ratios $\left(\mathbb{H}_{0}: \mathrm{HR}=1\right)$} \\
\hline Executive Constraints $\left(I N S_{0}\right)$ & $\begin{array}{c}-0.178^{* * *} \\
(0.058)\end{array}$ & $\begin{array}{c}-0.185^{* * *} \\
(0.067)\end{array}$ & $\begin{array}{c}1.229^{* * *} \\
(0.074)\end{array}$ & $\begin{array}{c}1.263^{* * *} \\
(0.089)\end{array}$ & $\begin{array}{c}1.222^{* * *} \\
(0.071)\end{array}$ & $\begin{array}{c}1.221^{* * *} \\
(0.082)\end{array}$ \\
\hline Fractionalization $(E L F 15)$ & $\begin{array}{c}0.016^{* * *} \\
(0.004)\end{array}$ & $\begin{array}{c}0.016^{* * *} \\
(0.005)\end{array}$ & $\begin{array}{c}0.978^{* * *} \\
(0.005)\end{array}$ & $\begin{array}{c}0.974^{* * *} \\
(0.007)\end{array}$ & $\begin{array}{c}0.979^{* * *} \\
(0.005)\end{array}$ & $\begin{array}{c}0.979^{* * *} \\
(0.006)\end{array}$ \\
\hline Initial ln GDP per capita & $\begin{array}{l}0.197^{*} \\
(0.106)\end{array}$ & $\begin{array}{c}0.235^{* *} \\
(0.112)\end{array}$ & $\begin{array}{c}0.787 \\
(0.119)\end{array}$ & $\begin{array}{c}0.765 \\
(0.146)\end{array}$ & $\begin{array}{l}0.786^{*} \\
(0.113)\end{array}$ & $\begin{array}{c}0.768 \\
(0.137)\end{array}$ \\
\hline Real US Interest Rate & $\begin{array}{c}0.087^{*} \\
(0.048)\end{array}$ & $\begin{array}{l}0.084^{*} \\
(0.051)\end{array}$ & $\begin{array}{c}0.947 \\
(0.058)\end{array}$ & $\begin{array}{c}0.928 \\
(0.061)\end{array}$ & $\begin{array}{c}0.949 \\
(0.057)\end{array}$ & $\begin{array}{c}0.951 \\
(0.064)\end{array}$ \\
\hline $\ln \sigma($ Log-normal $)$ & $\begin{array}{l}-0.065 \\
(0.093)\end{array}$ & & & & & \\
\hline $\ln \gamma($ Log-logistic) & & $\begin{array}{c}-0.580^{* * *} \\
(0.105)\end{array}$ & & & & \\
\hline $\ln p$ (Weibull) & & & & $\begin{array}{c}1.219^{* *} \\
(0.107)\end{array}$ & & \\
\hline$\gamma($ Gompertz) & & & & & $\begin{array}{c}0.985 \\
(0.030)\end{array}$ & \\
\hline Constant & $\begin{array}{l}-0.553 \\
(0.868)\end{array}$ & $\begin{array}{l}-0.856 \\
(0.901)\end{array}$ & $\begin{array}{l}1.830 \\
(2.432)\end{array}$ & $\begin{array}{l}1.723 \\
(2.884)\end{array}$ & $\begin{array}{l}1.928 \\
(2.448)\end{array}$ & \\
\hline Exits & 47 & 47 & 47 & 47 & 47 & 47 \\
\hline Spells & 57 & 57 & 57 & 57 & 57 & 57 \\
\hline Years of Decline & 346 & 346 & 346 & 346 & 346 & 346 \\
\hline $\log -\mathcal{L}$ & -72.090 & -73.286 & -75.295 & -73.940 & -75.192 & -143.142 \\
\hline AIC & 156.180 & 158.571 & 160.590 & 159.879 & 162.384 & 294.285 \\
\hline Pseudo-R ${ }^{2}$ & 0.168 & 0.164 & 0.208 & 0.210 & 0.160 & 0.088 \\
\hline
\end{tabular}

Models (3) to (6) in Table 5 have a different interpretation than all of the AFT models shown previously. We no longer report coefficients but instead hazard ratios, since these models are proportional hazards $(\mathrm{PH})$ models by nature. Only the Weibull and exponential distribution also have an equivalent AFT formulation. Hazard ratios are interpreted as follows. A hazard ratio greater than one implies a higher instantaneous probability of exiting the decline. A hazard ratio smaller than one implies a lower 
instantaneous probability of exiting the decline. Model (3) is the exponential or constant hazard model. Here too, the results are quantitatively and qualitatively very similar (given the altered interpretation), but the log-likelihood decreases somewhat and we have no reason to suspect a constant hazard. Model (4) uses a Weibull parametrization which allows for monotonically increasing or decreasing hazard rates. This model also has a shape parameter $(p)$ which allows testing for a constant hazard and, if constancy is rejected, indicates whether the rate increases or decreases. A Wald test of the null hypothesis that $\ln p=0$ rejects. However, contrary to all other parameterizations, the Weibull model suggests that the baseline hazard is increasing over time. The Gompertz model in column five also suggests a shape that is monotonically decreasing $(\gamma<0)$.

Which hazard shape fits the data best and is more intuitive? The question of fit is easily answered by the Akaike information criterion (AIC) which is commonly used for comparing non-nested models. The AIC is lowest for the log-normal model, confirming our choice. However, this does not tell us what the underlying baseline hazard looks like. In model (6), we specify a semi-parametric Cox model which does not restrict the shape of the baseline hazard. The Cox model also suggests that the probability of exiting a spell first increases very briefly and then decreases monotonically. This lends itself to the following interpretation. In the first few years of a decline, countries are suffering from a harsh but possibly temporary shock. Some countries are able to recover quickly. However, the longer the decline lasts, the more economic fundamentals deteriorate making it increasingly difficult to enter the recovery.

Table 6 - Robustness: heterogeneity, dropping regions, and multiple failures

\begin{tabular}{|c|c|c|c|c|c|c|}
\hline VARIABLES & $\begin{array}{l}(1) \\
\text { Full } \\
\ln \tilde{t}\end{array}$ & $\begin{array}{c}(2) \\
\text { No SSA } \\
\quad \ln \tilde{t} \\
\end{array}$ & $\begin{array}{c}(3) \\
\text { No MNA } \\
\ln \tilde{t}\end{array}$ & $\begin{array}{c}(4) \\
\text { No LAC } \\
\ln \tilde{t}\end{array}$ & $\begin{array}{c}(5) \\
\text { No multiple } \\
\ln \tilde{t}\end{array}$ & $\begin{array}{c}\text { PWP multiple } \\
\ln \tilde{t}\end{array}$ \\
\hline Executive Constraints $\left(I N S_{0}\right)$ & $\begin{array}{c}-0.161^{* * *} \\
(0.061)\end{array}$ & $\begin{array}{c}-0.159 * * * \\
(0.055)\end{array}$ & $\begin{array}{c}-0.199 * * * \\
(0.071)\end{array}$ & $\begin{array}{c}-0.189^{* *} \\
(0.074)\end{array}$ & $\begin{array}{c}-0.199 * * * \\
(0.064)\end{array}$ & $\begin{array}{c}1.263^{* * *} \\
(0.096)\end{array}$ \\
\hline Fractionalization (ELF15) & $\begin{array}{c}0.012^{* *} \\
(0.006)\end{array}$ & $\begin{array}{c}0.005 \\
(0.004)\end{array}$ & $\begin{array}{c}0.018^{* * *} \\
(0.005)\end{array}$ & $\begin{array}{c}0.016^{* * *} \\
(0.005)\end{array}$ & $\begin{array}{c}0.015^{* * *} \\
(0.004)\end{array}$ & $\begin{array}{c}0.981^{* * *} \\
(0.006)\end{array}$ \\
\hline Initial ln GDP per capita & $\begin{array}{l}0.213^{*} \\
(0.111)\end{array}$ & $\begin{array}{c}0.358^{* * *} \\
(0.101)\end{array}$ & $\begin{array}{l}0.263^{*} \\
(0.139)\end{array}$ & $\begin{array}{c}0.179 \\
(0.115)\end{array}$ & $\begin{array}{l}0.196^{*} \\
(0.111)\end{array}$ & $\begin{array}{c}0.759 \\
(0.137)\end{array}$ \\
\hline Real US Interest Rate & $\begin{array}{c}0.091^{* *} \\
(0.039)\end{array}$ & $\begin{array}{c}0.103^{* *} \\
(0.042)\end{array}$ & $\begin{array}{c}0.066 \\
(0.048)\end{array}$ & $\begin{array}{c}0.090 \\
(0.065)\end{array}$ & $\begin{array}{c}0.086 \\
(0.060)\end{array}$ & $\begin{array}{c}0.940 \\
(0.067)\end{array}$ \\
\hline Constant & $\begin{array}{c}-0.767 \\
(0.943)\end{array}$ & $\begin{array}{c}-1.843^{* *} \\
(0.936)\end{array}$ & $\begin{array}{l}-1.055 \\
(1.063)\end{array}$ & $\begin{array}{l}-0.393 \\
(0.870)\end{array}$ & $\begin{array}{l}-0.405 \\
(0.900)\end{array}$ & \\
\hline $\mathrm{VCE}$ & - & cluster & cluster & cluster & cluster & cluster \\
\hline Frailties & shared & - & - & - & - & - \\
\hline Strata & - & - & - & - & - & spell \# \\
\hline Exits & 47 & 40 & 43 & 34 & 40 & 47 \\
\hline Spells & 57 & 44 & 50 & 43 & 50 & 57 \\
\hline Years of Decline & 346 & 178 & 294 & 271 & 312 & 346 \\
\hline $\log -\mathcal{L}$ & -71.867 & -50.584 & -64.255 & -54.643 & -63.715 & -123.435 \\
\hline Pseudo- $R^{2}$ & 0.111 & 0.151 & 0.163 & 0.172 & 0.162 & 0.095 \\
\hline
\end{tabular}

Next, we turn to the issues of heterogeneity, influential observations and recurrent spells. The previous section has already shown that the effects in our preferred specification are robust to the inclusion of regional fixed-effects. Model (1) in Table 6 goes a step further and includes country-level effects in the model. Each country now has an unobserved effect or so-called gamma distributed frailty. These frailties are the duration analysis equivalent of random effects in linear models. The term frailty derives from the notion that a subject may be more 'frail' than the average, that is, more disposed to 
experiencing a certain event than others. As always, these random effects are assumed to be uncorrelated with any of the other included covariates (which is unlikely). Our results are robust to allowing for this type of country-specific heterogeneity. ${ }^{28}$

Models (2) to (4) examine if any of our main results are driven by specific regions with particularly long slumps. We address this issue by re-estimating our preferred model multiple times, each time removing one of the three regions with the longest spells. Model (2) drops all declines in Sub-Saharan Africa (SSA) and reveals an interesting additional finding. While the coefficient of fractionalization (ELF15) is very robust in the previous models, its size and significance is clearly driven by African observations. Without those, the coefficient keeps the same sign but shrinks substantially and becomes insignificant at conventional levels, while the partial effect of institutions remains significant. Since Sub-Saharan Africa has the greatest ethno-linguistic heterogeneity of all regions, this result is not too surprising. ${ }^{29}$ The interaction model proposed earlier may thus be more relevant to understanding the effects of institutions and fractionalization in Africa than elsewhere. On the other hand, models (3) and (4) show that the parameter estimates are not sensitive to excluding either the entire Middle East and North Africa (MNA) or all of Latin America and the Caribbean (LAC).

Until now, we assumed that multiple spells of the same type can be treated as interchangeable. The last two columns of Table 6 investigate if this relatively strong form of conditional independence is a reasonable assumption. Model (5) shows that our findings are robust to excluding all spells other than the first, which rules out any dependency across recurrent spells. The coefficient of executive constraints becomes even larger and the effect of fractionalization is virtually unchanged. Model (6) takes a different approach and specifies a conditional risk set model or stratified Cox model due to Prentice et al. (1981, PWP). The model accounts for ordering of the events but assumes that a subject cannot experience another event until the previous event has occurred. In our case, this is a natural assumption, as - by definition - a country cannot exit a second decline phase before having left the first and so on. Again, the results remain qualitatively and quantitatively similar, although the reported hazard ratios cannot be directly compared to the coefficients of the log-normal model.

In sum, we find that a log-normal hazard shape is not only a flexible assumption but offers an intuitive interpretation of the baseline hazard and fits the data best. Further, our main findings are robust to allowing for a restricted form of unobserved heterogeneity, dropping of influential regions, and accounting for dependency among recurrent events. An important additional insight is that the effect of fractionalization is driven by SubSaharan Africa, where fractionalization is highest and declines last the longest on average.

\section{Conclusion}

This paper makes three contributions to a burgeoning literature on growth episodes and structural breaks in growth performances. First, we show that a restricted structural change approach, as in Papell and Prodan (2012), works well as an inferential method for identifying slumps, big recessions or growth collapses in a large sample of countries. We find a substantial number of slumps in developing and developed countries alike,

\footnotetext{
${ }^{28}$ Interestingly, there is only weak evidence in favor of unobserved heterogeneity. A Likelihood Ratio test for the presence of shared frailties fails to reject the null $(p=0.252)$.

${ }^{29}$ In our sample, the average ELF15 score in Sub-Saharan Africa is 87 out of 100, compared to 62 in the Middle East and North Africa and 34 in Latin America and the Caribbean.
} 
suggesting that severe downward volatility is an ubiquitous phenomenon in the postwar period. Second, the slumps we identify have interesting characteristics, over and above the expected macroeconomic symptoms. Some of these factors have received little attention so far. Most prominently, we find systematic evidence of weak institutions before slumps hit and positive institutional change during and in the immediate aftermath of slumps. Our interpretation of this finding is that institutions may not only cause growth, but volatility can also contribute to endogenous institutional change. Severe economic crises bring about what we may call creative political destruction and raise the pressure for institutional reform in a very broad sense. Third, we find robust evidence that the duration until the exit of the decline phase depends on institutions and particularly strongly on ethno-linguistic fractionalization. Further, we show that the effect of institutions is non-linear and depends on the level of fractionalization.

As a whole, our results lend broad support to political economy theories emphasizing the respective roles of institutions and social conflict. Effective coordination and responses to slumps are hampered by a high degree of (latent) social tension as captured by ethno-linguistic fractionalization. However, particularly strong institutions can put in place coordination mechanisms that are able contain or resolve these conflicts within the institutional framework. On the other hand, our findings also suggest that in less ethnically fragmented societies institutions are less important as a determinant of the length of declines. These results do not suggest that sound macroeconomic policies as such do not matter, but they provide some indication that these policies may be secondary to more fundamental factors. In addition, while the previous literature has stressed the role of positive growth spurts, we show that slumps matter a lot and that the decline phase can last very long in some cases. In fact, given that growth has been found comparatively easy to ignite but difficult to sustain, a comparison of the relative effects of slumps versus accelerations on long-run GDP levels would be an interesting extension of our findings.

Many avenues are still left unexplored. For example, we did not analyze the determinants of the depth of slumps, which is a natural extension to a study of their duration. More work can be done on nesting different models of restricted structural change and statistically testing which pattern fits the data better. Last but not least, much of the growth episodes literature still falls short of convincing causal analysis. Future research should focus more on exploring the causal factors that are behind the occurrence, duration and magnitude of different growth episodes - a challenging but exciting area of research. 


\section{References}

Acemoglu, D. and S. Johnson (2005). Unbundling institutions. Journal of Political Economy 113(5), 949-95.

Acemoglu, D., S. Johnson, and J. A. Robinson (2001). The colonial origins of comparative development: An empirical investigation. American Economic Review 91(5), 1369-1401.

Acemoglu, D., S. Johnson, and J. A. Robinson (2002). Reversal of Fortune: Geography and Institutions in the Making of the Modern World Income Distribution. Quarterly Journal of Economics 117(4), $1231-1294$.

Acemoglu, D., S. Johnson, J. A. Robinson, and Y. Thaicharoen (2003). Institutional causes, macroeconomic symptoms: volatility, crises and growth. Journal of Monetary Economics 50(1), $49-123$.

Acemoglu, D. and J. A. Robinson (2006). Economic Origins of Democracy and Dictatorship. Cambridge University Press.

Acemoglu, D., J. A. Robinson, and T. Verdier (2004). Alfred Marshall Lecture: Kleptocracy and divideand-rule: a model of personal rule. Journal of the European Economic Association 2(2-3), 162-192.

Aguiar, M. and G. Gopinath (2007). Emerging market business cycles: The cycle is the trend. Journal of Political Economy 115(1), 69-102.

Andrews, D. W. K. (1993). Tests for parameter instability and structural change with unknown change point. Econometrica, 821-856.

Andrews, D. W. K. and W. Ploberger (1994). Optimal tests when a nuisance parameter is present only under the alternative. Econometrica, 1383-1414.

Bai, J. (1997). Estimating multiple breaks one at a time. Econometric Theory 13, 315-352.

Bai, J. (1999). Likelihood ratio tests for multiple structural changes. Journal of Econometrics 91(2), 299-323.

Bai, J. and P. Perron (1998). Estimating and testing linear models with multiple structural changes. Econometrica $66,47-78$.

Bai, J. and P. Perron (2003). Computation and analysis of multiple structural change models. Journal of Applied Econometrics 18(1), 1-22.

Barro, R. J. and J.-W. Lee (2010, April). A new data set of educational attainment in the world, 1950-2010. Working Paper 15902, National Bureau of Economic Research.

Beck, T., A. Demirgüç-Kunt, and R. Levine (2010). Financial institutions and markets across countries and over time: The updated financial development and structure database. The World Bank Economic Review 24(1), 77-92.

Beck, T., R. Levine, and N. Loayza (2000). Finance and the sources of growth. Journal of Financial Economics 58(12), $261-300$.

Ben-David, D. and D. H. Papell (1995). The great wars, the great crash, and steady state growth: Some new evidence about an old stylized fact. Journal of Monetary Economics 36(3), $453-475$.

Berg, A., J. D. Ostry, and J. Zettelmeyer (2012). What makes growth sustained? Journal of Development Economics 98(2), 149 - 166.

Besley, T. and T. Persson (2011). The logic of political violence. The Quarterly Journal of Economics 126(3), 1411-1445.

Bluhm, R., D. d. Crombrugghe, and A. Szirmai (2012). Explaining the dynamics of stagnation: An empirical examination of the north, wallis and weingast approach. UNU-MERIT Working Paper Series 040, United Nations University, Maastricht Economic and social Research and training centre on Innovation and Technology.

Bussière, M. and M. Fratzscher (2006). Towards a new early warning system of financial crises. Journal of International Money and Finance 25(6), 953-973.

Calvo, G. A., A. Izquierdo, and E. Talvi (2006, March). Phoenix miracles in emerging markets: Recovering without credit from systemic financial crises. Working Paper 12101, National Bureau of Economic Research.

Cameron, A. C., J. B. Gelbach, and D. L. Miller (2011). Robust inference with multiway clustering. Journal of Business 83 Economic Statistics 29(2), 238-249.

Cerra, V. and S. C. Saxena (2008). Growth dynamics: The myth of economic recovery. American Economic Review 98(1), 439-57.

Chinn, M. D. and H. Ito (2006). What matters for financial development? capital controls, institutions, 
and interactions. Journal of Development Economics 81(1), 163 - 192.

Desmet, K., I. Ortuno-Ortín, and R. Wacziarg (2012). The political economy of linguistic cleavages. Journal of Development Economics $97(2), 322$ - 338.

Diebold, F. X. and C. Chen (1996). Testing structural stability with endogenous breakpoint a size comparison of analytic and bootstrap procedures. Journal of Econometrics 70(1), 221-241.

Easterly, W., M. Kremer, L. Pritchett, and L. Summers (1993). Good policy or good luck? Journal of Monetary Economics 32(3), 459-483.

Easterly, W. and R. Levine (1997). Africa's growth tragedy: policies and ethnic divisions. The Quarterly Journal of Economics 112(4), 1203-1250.

Eichengreen, B., A. K. Rose, and C. Wyplosz (1995). Exchange market mayhem: the antecedents and aftermath of speculative attacks. Economic Policy 10(21), 249-312.

Frankel, J. and G. Saravelos (2012). Can leading indicators assess country vulnerability? evidence from the 2008-09 global financial crisis. Journal of International Economics 87(2), 216 - 231.

Gleditsch, N. P., P. Wallensteen, M. Eriksson, M. Sollenberg, and H. Strand (2002). Armed conflict 1946-2001: A new dataset. Journal of Peace Research 39(5), 615-637.

Goemans, H. E., K. S. Gleditsch, and G. Chiozza (2009). Introducing archigos: A dataset of political leaders. Journal of Peace Research 46(2), 269-283.

Gourinchas, P.-O. and M. Obstfeld (2012, January). Stories of the twentieth century for the twenty-first. American Economic Journal: Macroeconomics 4(1), 226-265.

Greif, A. and D. D. Laitin (2004). A theory of endogenous institutional change. American Political Science Review 98(04), 633-652.

Hansen, B. E. (2000). Testing for structural change in conditional models. Journal of Econometrics 97(1), 93-115.

Hausmann, R., J. Hwang, and D. Rodrik (2007). What you export matters. Journal of Economic Growth 12, 1-25.

Hausmann, R., L. Pritchett, and D. Rodrik (2005). Growth accelerations. Journal of Economic Growth 10(4), 303-329.

Hausmann, R., F. Rodriguez, and R. Wagner (2008). Growth collapses. In C. Reinhart, C. Vegh, and A. Velasco (Eds.), Money, Crises and Transition, pp. 376-428. Cambridge, Mass.: MIT Press.

Jones, B. F. and B. A. Olken (2008). The anatomy of start-stop growth. The Review of Economics and Statistics $90(3)$, pp. $582-587$.

Jonung, L. and T. Hagberg (2005, June). How costly was the crisis of the 1990s? a comparative analysis of the deepest crises in finland and sweden over the last 130 years. Economic Papers 224, European Commission.

Kalbfleisch, J. D. and R. L. Prentice (2002). The statistical analysis of failure time data (2nd ed.). New York: John Wiley.

Kaminsky, G. L. and C. M. Reinhart (1999). The twin crises: the causes of banking and balance-ofpayments problems. American Economic Review 89(3), 473-500.

King, R. G. and R. Levine (1993). Finance and growth: Schumpeter might be right. The Quarterly Journal of Economics 108(3), 717-737.

Klomp, J. and J. de Haan (2009). Political institutions and economic volatility. European Journal of Political Economy 25(3), 311-326.

Kose, M. A., E. Prasad, K. Rogoff, and S. J. Wei (2009). Financial globalization: A reappraisal. IMF Staff Papers 56(1), 8-62.

Lancaster, T. (1990). The econometric analysis of transition data. Cambridge University Press.

Lane, P. R. and G. M. Milesi-Ferretti (2007). The external wealth of nations mark ii: Revised and extended estimates of foreign assets and liabilities, 1970-2004. Journal of International Economics 73(2), $223-250$.

MacKinnon, J. (2009). Bootstrap hypothesis testing. In D. Belsley and E. Kontoghiorghes (Eds.), Handbook of Computational Econometrics, Chapter 6, pp. 183-213. John Wiley \& Sons, Ltd.

Mobarak, A. (2005). Democracy, volatility, and economic development. Review of Economics and Statistics 87(2), 348-361.

Nelson, C. R. and C. R. Plosser (1982). Trends and random walks in macroeconmic time series: some evidence and implications. Journal of Monetary Economics 10(2), 139-162.

North, D. C., J. Wallis, and B. Weingast (2009). Violence and Social Orders A Conceptual Framework for Interpreting Recorded Human History. Cambridge University Press. 
Papell, D. H. and R. Prodan (2012). The statistical behavior of GDP after financial crises and severe recessions. The B.E. Journal of Macroeconomics 12(3), 1-31.

Perron, P. and Z. Qu (2006). Estimating restricted structural change models. Journal of Econometrics 134(2), $373-399$.

Prentice, R. L., B. J. Williams, and A. V. Peterson (1981). On the regression analysis of multivariate failure time data. Biometrika 68(2), 373-379.

Pritchett, L. (2000). Understanding patterns of economic growth: searching for hills among plateaus, mountains, and plains. The World Bank Economic Review 14(2), 221-250.

Prodan, R. (2008). Potential pitfalls in determining multiple structural changes with an application to purchasing power parity. Journal of Business \& Economic Statistics 26(1), 50-65.

Reddy, S. and C. Minoiu (2009). Real income stagnation of countries 1960-2001. Journal of Development Studies 45(1), 1-23.

Rodrik, D. (1999). Where did all the growth go? External shocks, social conflict, and growth collapses. Journal of Economic Growth 4(4), 385-412.

Rodrik, D. (2008). The real exchange rate and economic growth. Brookings Papers on Economic Activity 2008(2), 365-412.

Sachs, J. D. and A. Warner (1995). Economic reform and the process of global integration. Brookings Papers on Economic Activity 1995(1), 1-118.

Silverberg, G. and B. Verspagen (2003). Long memory and economic growth in the world economy since the 19th century. In G. Rangarajan and M. Ding (Eds.), Processes with Long-Range Correlations, Volume 621 of Lecture Notes in Physics, pp. 270-285. Springer Berlin Heidelberg.

Solt, F. (2009). Standardizing the World Income Inequality Database. Social Science Quarterly 90(2), 231-242. SWIID Version 3.0, July 2010.

Thompson, S. B. (2011). Simple formulas for standard errors that cluster by both firm and time. Journal of Financial Economics 99(1), 1-10.

Wacziarg, R. and K. H. Welch (2008). Trade liberalization and growth: New evidence. The World Bank Economic Review 22(2), 187-231.

Wooldridge, J. M. (2010). Econometric analysis of cross section and panel data (2nd ed.). The MIT press.

Zivot, E. and D. W. K. Andrews (1992). Further evidence on the great crash, the oil-price shock, and the unit-root hypothesis. Journal of Business $\& 3$ Economic Statistics 10(3), 251-270. 


\section{A Appendix: Estimation of Structural Breaks}

\section{A.1 Sequential procedure for testing and dating breaks}

The procedure described here is a modification of Bai's (1997) sequential likelihood ratio tests for structural change - see also the extensions in Bai and Perron (1998) and in Bai (1999). We make an important simplifying assumption, namely, that all output series are regime-wise trend-stationary. Verifying this assumption is beyond the scope of this paper, as testing for unit roots in the presence of structural breaks (with sufficient power and size) is still contested territory and our output series have only a moderate time dimension $(T<60)$. Our implementation of the sequential procedure involves six steps:

1. Determine the optimal $A R(p)$ trend model using the Bayesian information criterion to adjust for serial correlation up to a maximum lag count $\left(p_{\max }\right)$. We set $p_{\max }=4$.

2. Specify the partial structural change model:

$y_{t}=\alpha+\beta t+\gamma_{0} \mathbf{1}\left(t>t b_{1}\right)+\gamma_{1}\left(t-t b_{1}\right) \mathbf{1}\left(t>t b_{1}\right)+\gamma_{2}\left(t-t b_{2}\right) \mathbf{1}\left(t>t b_{2}\right)+\sum_{i=1}^{p} \delta_{i} y_{t-i}+\epsilon_{t}$

where $y_{t}$ is the log of GDP per capita in year $t, t b_{i}$ are the possible break dates, $\mathbf{1}(\cdot)$ is an indicator function, and $p$ is the lag order as determined by the optimal $A R(p)$ model. We require that $t b_{2} \geq t b_{1}+h$ for $h=4$. In other words, the period between two successive breaks making up the same episode is at minimum 4 years.

3. Define trimming parameter $\tau$, where typically $\tau \in[0.05,0.25]$. The resulting estimation sample $\left(\Lambda_{\tau}\right)$ runs over $[\tau T,(1-\tau) T] .{ }^{30}$ The breaks are in the ranges $\widehat{t b}_{1} \in[\tau T,(1-\tau) T-h]$ and $\widehat{t b}_{2} \in[\tau T+h,(1-\tau) T]$. We set $\tau=0.05$.

4. Compute the sup- $W$ test statistic of the null of no break versus two breaks $\left(\mathbb{H}_{0}\right.$ : $\left.\gamma_{0}=\gamma_{1}=\gamma_{2}=0\right)$ over $t \in \Lambda_{\tau}$, under the restrictions that $\beta>0$ and $\gamma_{0}<0$ :

$$
\sup _{t \in \Lambda_{\tau}} W\left(\widehat{t b}_{1}^{1}, \ldots, \widehat{t b}_{1}^{c} ; \widehat{t b}_{2}^{1}, \ldots, \widehat{t b}_{2}^{d} ; q\right)=\sup _{t \in \Lambda_{\tau}}\left(\frac{T-k_{m}}{q}\right) \frac{S S R_{T}^{r}-S S R_{T}^{u}}{S S R_{T}^{u}}
$$

where $q=3, k_{m}$ is the number of parameters and $S S R_{T}^{r}$ denotes the sum of squared residuals under $\mathbb{H}_{0}$ and $S S R_{T}^{u}$ are the sum of squared residuals under $\mathbb{H}_{A}$.

5. The critical value and empirical p-value of $\sup _{t \in \Lambda_{\tau}} W\left(\widehat{t b}_{1}, \widehat{t b}_{2} ; q\right)$ is bootstrapped, as in finite samples comparable asymptotic tests often have poor size and power. ${ }^{31}$

6. If the sup- $W$ statistic is significant at the desired level, the sample is split into two new sub-samples from the beginning to the first break and from the second break to the end, then the procedure restarts at (4) using the estimated AR-order from before. If the bootstrapped $\sup W^{*}$ test fails to reject in each sub-sample, or the sub-samples are too small $(T \leq 20)$, then the procedure stops and all break pairs have been found.

\footnotetext{
${ }^{30}$ For simplicity of exposition, we suppress an additional index running over the sub-samples (defined in Step 6). $T$ refers to the number of observations of the currently active sample.

${ }^{31}$ See, for example, Prodan (2008) who documents such poor finite sample properties for the BaiPerron multiple structural breaks procedure and recommends the bootstrap.
} 


\section{A.2 Bootstrapping the sup-Wald statistic}

There have been several suggestions on how to best bootstrap structural change tests in particular or other popular time-series tests in general. For example, Hansen (2000) suggests employing a fixed-design bootstrap allowing for non-stationarity, lagged dependent variables and conditional heteroskedasticity. MacKinnon (2009), on the contrary, shows that the recursive bootstrap of Diebold and Chen (1996) gives results superior to most other bootstrap types (fixed-parameter, Sieve, pairs, block, double block) and the asymptotic test in a simple application of an $\mathrm{AR}(1)$ model with an endogenous break. Similarly, Papell and Prodan (2012) also favor a recursive bootstrap but do not compare it to other methods. Hence, we use a recursive bootstrap similar to Diebold and Chen (1996) as comparing these methods systematically is also well beyond the scope of this paper. ${ }^{32}$ In line with usual notation, we denote all bootstrap quantities with the superscript ${ }^{~ *}$ '. The bootstrap procedure is as follows:

1. Specify the optimal break model under the $\mathbb{H}_{0}$ of no structural breaks in the specified sample using the BIC as before and obtain the residuals:

$$
\hat{e}_{t}=y_{t}-\hat{\alpha}-\hat{\beta} t-\sum_{i=1}^{p} \hat{\delta}_{i} y_{t-i}
$$

2. Draw new residuals: $\hat{e}_{t}^{*}=u_{t}$, with $u_{t} \sim$ i.i.d. $\mathcal{N}\left(0, \sigma_{\hat{e}}^{2}\right)$

3. Construct a bootstrap sample of equal size as the original sample:

$$
y_{t}^{*}=\hat{\alpha}+\hat{\beta} t+\sum_{i=1}^{p} \hat{\delta}_{i} y_{t-i}^{*}+\hat{e}_{t}^{*}, \quad \forall t=1+p, \ldots, T
$$

where $y_{t-i}^{*}$ is the observed $y_{t-i}$ only in the case of a fixed-design bootstrap, otherwise $y_{t}^{*}$ must be constructed recursively (conditional on $p$ observed initial values of $\left\{y_{t}\right\}$ ).

4. Rerun the break search algorithm on the bootstrap series $\left\{y_{t}^{*}\right\}$, including determination of the optimal $\operatorname{AR}(p)$ model, and compute bootstrapped $\sup W^{*}$ test statistic $\sup _{t \in \Lambda_{\tau}}^{i} W^{*}\left(\widehat{t b}_{1}^{*}, \widehat{t b}_{2}^{*} ; q\right)$, where $i$ indexes the current bootstrap iteration.

5. Repeat from Step (2) until $i=B$, where $B$ is the total number of bootstrap replications. We set $B=1000$.

6. The bootstrap $p$-value $\left(\hat{p}^{*}\right)$ is obtained by counting the proportion the estimated bootstrap test statistics are greater than the originally estimated test statistic:

$$
\hat{p}^{*}=\frac{1}{B} \sum_{i=1}^{B} \mathbf{1}\left(\sup _{\widehat{t b}_{1}^{*}, \widehat{b b}_{2}^{*} \in \Lambda_{\tau}} W^{*}\left(\widehat{t b}_{1}^{*}, \widehat{t b}_{2}^{*} ; q\right)>\sup _{\widehat{t} \widehat{b}_{1}, \widehat{t b}_{2} \in \Lambda_{\tau}} W\left(\widehat{t b}_{1}, \widehat{t b}_{2} ; q\right)\right)
$$

and the critical value corresponds to the $i^{\text {th }}=\left(1-\alpha^{s}\right) B$ element of the sorted vector of bootstrap statistics $\Gamma=\left[\sup _{t \in \Lambda_{\tau}}^{\min } W^{*}(\cdot), \ldots, \sup _{t \in \Lambda_{\tau}}^{\max } W^{*}(\cdot)\right]$, where $\alpha^{s}$ is the desired significance level (10\% throughout the text, if not otherwise noted).

\footnotetext{
${ }^{32}$ We use a parametric recursive bootstrap, but informally compared the results to other techniques. Hansen's fixed-design bootstrap generates (too) many questionable slumps and the Wild bootstrap rejects (too) often. Residual and parametric bootstraps give similar results. A systematic comparison is planned.
} 


\section{B Appendix: List of Episodes}

Table 7 - Global Parameters

\begin{tabular}{|lc|lc|}
\hline Data: & PWT & Max AR $\left(p_{\max }\right):$ & 4 \\
Sample start: & 1950 & Bootstrap replications: & 1000 \\
Sample end: & 2008 & Bootstrap errors: & parametric \\
Trimming $(\tau):$ & 0.05 & Bootstrap type: & recursive \\
Min. $t b_{i}$ distance $(h):$ & 4 & Bootstrap significance $\left(\alpha^{s}\right):$ & 0.1 \\
\hline
\end{tabular}

Table 8 - Estimated and Filtered Breaks with Troughs: 58 Episodes*

\begin{tabular}{|c|c|c|c|c|c|c|c|c|c|c|c|}
\hline Code & $T_{0}$ & $\widehat{t b_{1}}$ & $\widehat{t}_{\min }$ & $\widehat{t b b_{2}}$ & $T$ & Sup- $W$ & Critical $W$ & $\mathrm{p}$-value & Drop (\%) & Duration & $c$ \\
\hline ALB & 1970 & 1990 & 1991 & 2002 & 2008 & 18.5 & 13.6 & 0.007 & -15.32 & 1 & 0 \\
\hline ARE & 1986 & 1990 & 1999 & 2002 & 2008 & 29.1 & 14.5 & 0.003 & -10.90 & 9 & 0 \\
\hline AUS & 1950 & 1954 & 1957 & 1966 & 2008 & 8.3 & 8.7 & 0.064 & -0.72 & 3 & 0 \\
\hline AUS & 1967 & 1989 & 1991 & 1998 & 2008 & 10.1 & 10.7 & 0.059 & -2.29 & 2 & 0 \\
\hline BDI & 1960 & 1971 & 1972 & 1988 & 2008 & 9.9 & 11.3 & 0.089 & -3.23 & 1 & 0 \\
\hline BEL & 1950 & 1957 & 1958 & 1973 & 2008 & 12.8 & 12.1 & 0.029 & -2.24 & 1 & 0 \\
\hline BGR & 1970 & 1988 & 1997 & 1997 & 2008 & 16.3 & 12.8 & 0.010 & -23.79 & 9 & 0 \\
\hline BHR & 1970 & 1980 & 1987 & 1986 & 2008 & 14.4 & 11.0 & 0.010 & -44.12 & 7 & 1 \\
\hline BRA & 1950 & 1980 & 1983 & 2003 & 2008 & 12.5 & 12.3 & 0.043 & -14.60 & 3 & 0 \\
\hline CAF & 1960 & 1978 & 2005 & 2005 & 2008 & 8.3 & 8.7 & 0.060 & -46.38 & 27 & 1 \\
\hline $\mathrm{CHE}$ & 1950 & 1974 & 1975 & 1978 & 2008 & 10.7 & 10.6 & 0.047 & -7.87 & 1 & 0 \\
\hline CHL & 1951 & 1953 & 1954 & 1972 & 1973 & 12.0 & 8.5 & 0.017 & -9.06 & 1 & 0 \\
\hline CHL & 1951 & 1974 & 1975 & 1979 & 1980 & 13.3 & 10.8 & 0.021 & -16.50 & 1 & 0 \\
\hline CHL & 1951 & 1981 & 1983 & 1995 & 2008 & 12.6 & 11.4 & 0.025 & -21.22 & 2 & 0 \\
\hline CHN & 1952 & 1960 & 1962 & 1977 & 2008 & 13.9 & 12.9 & 0.029 & -23.71 & 2 & 0 \\
\hline CMR & 1960 & 1986 & 1995 & 1990 & 2008 & 12.0 & 12.3 & 0.055 & -40.46 & 9 & 1 \\
\hline $\mathrm{COG}$ & 1960 & 1974 & 1977 & 1982 & 2008 & 11.9 & 12.5 & 0.069 & -21.35 & 3 & 0 \\
\hline CRI & 1950 & 1955 & 1956 & 1963 & 1979 & 11.4 & 11.3 & 0.048 & -4.39 & 1 & 0 \\
\hline CRI & 1950 & 1980 & 1982 & 2002 & 2008 & 17.2 & 10.6 & 0.002 & -17.47 & 2 & 0 \\
\hline CUB & 1970 & 1988 & 1993 & 1995 & 2008 & 11.4 & 12.5 & 0.072 & -34.70 & 5 & 0 \\
\hline CYP & 1950 & 1973 & 1975 & 1977 & 2008 & 15.5 & 9.7 & 0.001 & -31.40 & 2 & 0 \\
\hline CYP & 1978 & 1990 & 1991 & 1995 & 2008 & 11.6 & 14.6 & 0.098 & -10.19 & 1 & 0 \\
\hline DNK & 1950 & 1954 & 1955 & 1965 & 2008 & 12.9 & 11.7 & 0.022 & -1.56 & 1 & 0 \\
\hline DZA & 1960 & 1984 & 1994 & 1996 & 2008 & 10.9 & 8.2 & 0.013 & -14.09 & 10 & 0 \\
\hline ETH & 1950 & 1972 & 1992 & 1993 & 2008 & 11.5 & 10.2 & 0.020 & -30.68 & 20 & 0 \\
\hline FIN & 1950 & 1989 & 1993 & 2006 & 2008 & 10.6 & 10.8 & 0.057 & -16.34 & 4 & 0 \\
\hline GAB & 1960 & 1976 & 1987 & 1997 & 2008 & 10.6 & 11.2 & 0.062 & -50.56 & 11 & 1 \\
\hline GMB & 1960 & 1982 & 1998 & 2002 & 2008 & 16.4 & 11.2 & 0.006 & -25.33 & 16 & 0 \\
\hline GRC & 1951 & 1973 & 1974 & 1994 & 2008 & 17.9 & 11.6 & 0.003 & -6.92 & 1 & 0 \\
\hline GTM & 1950 & 1980 & 1988 & 1984 & 2008 & 15.1 & 12.3 & 0.015 & -19.14 & 8 & 0 \\
\hline HUN & 1970 & 1990 & 1992 & 2004 & 2008 & 15.6 & 13.5 & 0.018 & -10.56 & 2 & 0 \\
\hline IDN & 1960 & 1997 & 1999 & 2001 & 2008 & 13.5 & 10.6 & 0.013 & -17.49 & 2 & 0 \\
\hline IRN & 1955 & 1976 & 1981 & 1980 & 2008 & 15.9 & 11.6 & 0.004 & -56.78 & 5 & 1 \\
\hline IRQ & 1970 & 1990 & 2003 & 1994 & 2008 & 9.1 & 8.9 & 0.046 & -66.43 & 13 & 1 \\
\hline JPN & 1950 & 1973 & 1974 & 1990 & 2008 & 13.5 & 13.4 & 0.050 & -2.85 & 1 & 0 \\
\hline MEX & 1950 & 1981 & 1988 & 1995 & 2008 & 11.9 & 11.0 & 0.038 & -17.03 & 7 & 0 \\
\hline MNG & 1970 & 1990 & 1993 & 2003 & 2008 & 46.5 & 11.7 & 0.000 & -41.81 & 3 & 0 \\
\hline MOZ & 1960 & 1981 & 1986 & 1995 & 2008 & 12.6 & 12.0 & 0.037 & -24.99 & 5 & 0 \\
\hline MYS & 1955 & 1984 & 1986 & 1993 & 2008 & 9.1 & 10.5 & 0.093 & -7.47 & 2 & 0 \\
\hline NPL & 1960 & 1979 & 1980 & 2000 & 2008 & 10.6 & 8.9 & 0.025 & -5.33 & 1 & 0 \\
\hline NZL & 1950 & 1974 & 1978 & 1992 & 2008 & 9.9 & 10.5 & 0.070 & -9.03 & 4 & 0 \\
\hline
\end{tabular}


Table 8 - Continued from previous page

\begin{tabular}{lccccccccccc}
\hline Code & $T_{0}$ & $\widehat{t b}_{1}$ & $\widehat{t}_{\min }$ & $\widehat{t b}_{2}$ & $T$ & $\mathrm{Sup}-W$ & Critical $W$ & $\mathrm{p}$-value & Drop (\%) & Duration & $c$ \\
\hline OMN & 1970 & 1979 & 1980 & 1985 & 2008 & 12.4 & 9.0 & 0.007 & -21.61 & 1 & 0 \\
PER & 1950 & 1958 & 1959 & 1966 & 1976 & 11.9 & 9.3 & 0.022 & -6.91 & 1 & 0 \\
PER & 1950 & 1977 & 1992 & 1992 & 2008 & 11.0 & 10.3 & 0.037 & -29.30 & 15 & 0 \\
PHL & 1950 & 1983 & 1985 & 2003 & 2008 & 12.8 & 10.2 & 0.007 & -16.78 & 2 & 0 \\
POL & 1970 & 1979 & 1982 & 1993 & 2008 & 13.8 & 12.1 & 0.027 & -22.55 & 3 & 0 \\
PRY & 1980 & 1989 & 2002 & 2002 & 2008 & 8.8 & 8.8 & 0.049 & -14.24 & 13 & 1 \\
RWA & 1960 & 1993 & 1994 & 1997 & 2008 & 18.0 & 7.9 & 0.001 & -45.38 & 1 & 0 \\
SAU & 1986 & 1992 & 1999 & 2002 & 2008 & 14.6 & 13.3 & 0.039 & -18.75 & 7 & 0 \\
SLE & 1961 & 1995 & 1999 & 2006 & 2008 & 14.2 & 11.1 & 0.011 & -41.65 & 4 & 1 \\
SLV & 1950 & 1978 & 1983 & 1987 & 2008 & 18.2 & 10.2 & 0.002 & -25.82 & 5 & 0 \\
TGO & 1960 & 1979 & 2008 & 1989 & 2008 & 9.6 & 10.1 & 0.065 & -53.60 & 29 & 1 \\
THA & 1950 & 1996 & 1998 & 2003 & 2008 & 10.7 & 7.8 & 0.003 & -14.17 & 2 & 0 \\
TTO & 1950 & 1961 & 1963 & 1969 & 1981 & 16.8 & 14.9 & 0.020 & -0.78 & 2 & 0 \\
TTO & 1950 & 1982 & 1993 & 2006 & 2008 & 12.4 & 12.6 & 0.054 & -28.96 & 11 \\
UGA & 1950 & 1977 & 1986 & 1987 & 2008 & 11.6 & 10.5 & 0.029 & -30.27 & 9 & 0 \\
USA & 1950 & 1957 & 1958 & 1966 & 2008 & 8.7 & 9.3 & 0.075 & -2.51 & 1 \\
ZMB & 1955 & 1968 & 2001 & 2000 & 2008 & 15.0 & 10.9 & 0.007 & -68.99 & 33 & 0 \\
\hline \hline
\end{tabular}

* Out of a total of 70 episodes identified by the sequential algorithm, 12 are invalid slumps. The invalid episodes are [country code (spell number)]: AUT (1), AUT (2), CHN (1), FIN (1), HKG (1), IRN (1), MRT (1), PRY (1), TZA (1). 


\section{Appendix: Data Sources and Summary Statistics}

Table 9 - Summary Statistics: break date to trough

\begin{tabular}{|c|c|c|c|c|}
\hline VARIABLE & Mean & Std. Dev. & $N \times T$ & Source \\
\hline \multicolumn{5}{|c|}{ Institutions, Politics \& Conflict } \\
\hline Polity Score & -1.90 & 6.99 & 346 & Polity IV \\
\hline Democracy & 2.73 & 3.61 & 330 & Polity IV \\
\hline Autocracy & 4.69 & 3.74 & 330 & Polity IV \\
\hline Executive Recruitment & 4.92 & 2.27 & 330 & Polity IV \\
\hline Executive Constraints & 3.18 & 2.28 & 330 & Polity IV \\
\hline Political Competition & 4.11 & 3.38 & 330 & Polity IV \\
\hline Regime Duration & 18.14 & 22.70 & 347 & Polity IV \\
\hline Negative Regime Change & 0.01 & 0.12 & 347 & Polity IV \\
\hline Positive Regime Change & 0.10 & 0.29 & 347 & Polity IV \\
\hline Corruption (ICRG) & 2.63 & 1.10 & 193 & ICRG \\
\hline Fractionalization (ELF1) & 18.36 & 18.69 & 348 & Desmet et al. (2012) \\
\hline Fractionalization (ELF15) & 63.68 & 30.71 & 348 & Desmet et al. (2012) \\
\hline Inequality (Gini) & 45.83 & 11.65 & 192 & Solt $(2009)$ \\
\hline Leader Exit & 0.39 & 0.49 & 344 & Goemans et al. (2009) \\
\hline War/Conflict (major) & 0.12 & 0.33 & 348 & Gleditsch et al. (2002) \\
\hline War/Conflict (any) & 0.24 & 0.43 & 348 & Gleditsch et al. (2002) \\
\hline \multicolumn{5}{|c|}{ Macro I: Prices, Trade ES Exports } \\
\hline Inflation $(\ln (1+\delta))$ & 22.89 & 43.97 & 292 & WDI/IFS \\
\hline RER Undervalue & 0.07 & 0.54 & 348 & PWT 7.0 \\
\hline Current Account Balance ( $\%$ of GDP) & -3.98 & 6.70 & 254 & WDI \\
\hline$\Delta$ Terms of Trade & -4.11 & 17.72 & 224 & WDI/IFS \\
\hline Manufactures (\% of Exports) & 22.65 & 24.27 & 264 & WITS/ COMTRADE \\
\hline Trade Openness (de facto) & 67.85 & 37.43 & 348 & PWT 7.0 \\
\hline Trade Openness (de jure) & 0.23 & 0.42 & 306 & Wacziarg and Welch (2008) \\
\hline Export Sophisticaton & 8.43 & 0.42 & 234 & Hausmann et al. (2007) \\
\hline$\Delta$ Export Sophistication & 1.48 & 7.44 & 233 & Hausmann et al. (2007) \\
\hline Export Diversification & 65.91 & 24.58 & 264 & WITS/ COMTRADE \\
\hline \multicolumn{5}{|c|}{ Macro II: Finance } \\
\hline Capital Account Openness & -0.49 & 1.28 & 304 & Chinn and Ito (2006) \\
\hline Financial Integration & 115.30 & 88.18 & 309 & Lane and Milesi-Ferretti (2007) \\
\hline Financial Depth & 32.35 & 18.68 & 245 & Beck et al. (2010) \\
\hline Financial Development & 68.40 & 22.18 & 271 & Beck et al. (2010) \\
\hline Private Credit (\% of GDP) & 26.25 & 23.53 & 248 & Beck et al. (2010) \\
\hline FDI Liabilities ( $\%$ of GDP) & 15.11 & 15.66 & 309 & Lane and Milesi-Ferretti (2007) \\
\hline External Debt Liabilities ( $\%$ of GDP) & 65.22 & 59.18 & 309 & Lane and Milesi-Ferretti (2007) \\
\hline External Leverage $^{\mathrm{a}}$ & 165.29 & 327.09 & 307 & Lane and Milesi-Ferretti (2007) \\
\hline \multicolumn{5}{|c|}{ Other Determinants } \\
\hline Initial ln GDP per capita $^{b}$ & 8.20 & 1.21 & 348 & PWT 7.0 \\
\hline Real US Interest Rate ${ }^{\mathrm{c}}$ & 1.90 & 2.44 & 348 & FRED \\
\hline Infant Mortality $^{\mathrm{d}}$ & 73.37 & 40.23 & 348 & World Population Prospects \\
\hline Life Expectancy ${ }^{\mathrm{d}}$ & 58.63 & 10.55 & 348 & World Population Prospects \\
\hline Telephones (per 100 people) & 5.24 & 9.78 & 312 & WDI \\
\hline Education (primary) & 3.14 & 1.71 & 327 & Barro and Lee (2010) \\
\hline Education (secondary) & 1.12 & 0.83 & 327 & Barro and Lee (2010) \\
\hline Education (all) & 4.44 & 2.47 & 327 & Barro and Lee (2010) \\
\hline
\end{tabular}

${ }^{\mathrm{a}}$ Following Gourinchas and Obstfeld (2012), external leverage is $l_{i}=\left(\tau+A_{i} / Y_{i}\right)\left(\tau+N A_{i} / Y_{i}+E_{i j} / Y_{i}\right)^{-1}$, where $\tau$ is the market value of assets to output (set to 3 ) and $j$ is the rest of the world, $A_{i} / Y_{i}$ is assets over GDP, $N A_{i} / Y_{i}$ is net foreign assets over GDP and $E_{i j} / Y_{i}$ equity over GDP. The ratio is always $>0$ if $N A_{i}>-300$, this condition is not satisfied in very few cases; we set these missing.

${ }^{\mathrm{b}}$ Initial refers to $\ln$ GDP per capita at $t_{0}$, that is, the last year before the slump.

${ }^{\mathrm{c}}$ Deflated three months treasury bill rate.

${ }^{\mathrm{d}}$ Converted into annual data by interpolation. If the average is for the years 1950-55, we assume it is reached in the 1952 and linearly interpolate to the middle of the next group (1957), and so on. The data is from the 2010 edition of the Word Population Prospects (medium-fertility variant). 


\section{Appendix: Duration Method}

\section{Log-normal Accelerated Failure Time (AFT) models}

Given the model $\ln (\tilde{t})=\beta_{0}+\mathbf{x}^{\prime} \boldsymbol{\beta}+\epsilon$, log-normality implies the following relationships. Setting all covariates zero, the expected survival time is $\mathrm{E}[\ln t \mid \boldsymbol{\beta}=\mathbf{0}]=\beta_{0}$. Hence, the baseline survival and hazard functions are

$$
S_{0}(\tilde{t})=1-\Phi\left(\left(\ln \tilde{t}-\beta_{0}\right) \sigma^{-1}\right) \quad \text { and } \quad \lambda_{0}(\tilde{t})=\frac{\phi\left(\left(\ln \tilde{t}-\beta_{0}\right) \sigma^{-1}\right)}{\left(1-\Phi\left(\left(\ln \tilde{t}-\beta_{0}\right) \sigma^{-1}\right)\right) \sigma \tilde{t}}
$$

where $\phi(\cdot)$ and $\Phi(\cdot)$ are the standard normal pdf and normal cdf, respectively.

Including (time-invariant) covariates is equivalent to scaling the baseline survival functions. The conditional survival curve is defined as $S(\tilde{t} \mid \mathbf{x})=S_{0}(\tilde{t})\left(\exp \left(-\mathbf{x}^{\prime} \boldsymbol{\beta}\right) \tilde{t}\right)$. This implies $S(\tilde{t} \mid \mathbf{x})=1-\Phi\left(\left(\ln \tilde{t}-\left(\beta_{0}+\mathbf{x}^{\prime} \boldsymbol{\beta}\right)\right) \sigma^{-1}\right)$; that is, the intercept can be absorbed into $\boldsymbol{\beta}$. The density and cumulative probability functions are defined implicitly. ${ }^{33}$

Time-varying covariates introduce two complications. First, the hazard rate at each unit of analysis time $\tilde{t}$ is not independent from previous realizations of the time-varying covariates. Second, the covariates must be strictly exogenous, as otherwise feedback may occur from the duration to future realizations of the covariates. Following Lancaster (1990) and Kalbfleisch and Prentice (2002) these issues can be formalized as follows. For time-varying covariates $\mathbf{x}(\tilde{t})$, let $\mathbf{x}^{H}(\tilde{t})$ denote the covariate path up until time $\tilde{t}$, so that $\mathbf{x}^{H}(\tilde{t}) \equiv\{\mathbf{x}(u), 0 \leq u \leq \tilde{t}\}$ for all $\tilde{t} \geq 0$, then the conditional hazard function is:

$$
\lambda\left(\tilde{t} \mid \mathbf{x}^{H}\right)=\lim _{d \tilde{t}->0} \frac{\operatorname{Pr}\left(\tilde{t} \leq \tilde{T}<\tilde{t}+d \tilde{t} \mid \tilde{T} \geq \tilde{t}, \mathbf{x}^{H}(\tilde{t}+d \tilde{t})\right)}{d \tilde{t}}
$$

Lancaster (1990, pp. 26-30) and Kalbfleisch and Prentice (2002, p. 196) define strict exogeneity as $\operatorname{Pr}\left(\mathbf{x}^{H}(\tilde{t}) \mid \mathbf{x}^{H}(u), \tilde{T} \geq u\right)=\operatorname{Pr}\left(\mathbf{x}^{H}(\tilde{t}) \mid \mathbf{x}^{H}(u), \tilde{T}=u\right)$ for all $0<u \leq \tilde{t}$. The condition states that the future path of the time-varying covariate is not affected by the event occurring at present.

We can now derive the partial likelihood. ${ }^{34}$ Suppose we know the event occurs at $\tilde{t}_{i}$, the likelihood contribution of an observation $i$ at time $j=\tilde{t}_{i}$ then is $\mathcal{L}_{i}=f(j)=S(j) \lambda(j)$. The likelihood contribution of an observation that has not failed at time $j$, so that $j<\tilde{t}_{i}$, then is just the probability of survival until $j: \mathcal{L}_{i}=f(j)=S(j)$. Hence, right-censoring is essentially nothing else than an observation at analysis time $j$ that is still in the sample but has not yet failed and thus extends easily to (exogenous) time-varying covariates.

Using the notation for grouped data from Wooldridge (2010, p. 1016), the loglikelihood of the log-normal model with time-varying covariates can be expressed as:

$$
\ln \mathcal{L}(\boldsymbol{\beta}, \sigma)=\sum_{i=1}^{N}\left[\sum_{j=1}^{\tilde{t}_{i}-1} \ln \alpha_{j}\left(\mathbf{x}_{i j}^{\prime} \boldsymbol{\beta}, \sigma\right)+\left(1-c_{i}\right) \ln \left(1-\alpha_{\tilde{t}_{i}}\left(\mathbf{x}_{i \tilde{t}_{i}}^{\prime} \boldsymbol{\beta}, \sigma\right)\right)\right]
$$

where $\alpha_{j}(\cdot)=\exp \left[-\int_{\alpha_{j}-1}^{\alpha_{j}} \lambda(s, \cdot) d s\right]$ measures survival over the given interval and $c_{i}$ indicates if observation $i$ is censored. The inner sum (first term) is the probability of survival until $\tilde{t}_{i}-1$ and the second term is the conditional probability of failure at $\tilde{t}_{i}$.

\footnotetext{
${ }^{33}$ It follows that an expression for the ( $\log$ ) hazard function conditional on the covariates is $\ln \lambda(\tilde{t} \mid \mathbf{x})=$ $\ln \lambda_{0}\left(\tilde{t} \exp \left(-\mathbf{x}^{\prime} \boldsymbol{\beta}\right)\right)-\mathbf{x}^{\prime} \boldsymbol{\beta}$; these hazards are not proportional.

${ }^{34}$ This does not apply to frailty models where the likelihoods are more involved.
} 


\section{E Appendix: Variable Selection}

Table 10 - Base Models

\begin{tabular}{lccccccc}
\hline \hline & Coefficient & SE & p-value & Exits & Spells & Years & $\log \mathcal{L}$ \\
\hline Constant Only & 1.346 & 0.180 & 0.00 & 48 & 58 & 348 & -87.86 \\
Initial ln GDP per capita & -0.124 & 0.144 & 0.39 & 48 & 58 & 348 & -87.44 \\
Real US Interest Rate & 0.096 & 0.047 & 0.04 & 48 & 58 & 348 & -86.55 \\
\hline \hline
\end{tabular}

$\operatorname{Note}(s)$ : The second and third model also include a constant. The standard errors are clustered on the country level.

Table 11 - Variable Selection

\begin{tabular}{|c|c|c|c|c|c|c|c|}
\hline & Coefficient & $\mathrm{SE}$ & $\mathrm{p}$-value & Exits & Spells & Years & $\log \mathcal{L}$ \\
\hline Inflation $(\ln (1+\delta))$ & -0.002 & 0.004 & 0.68 & 38 & 45 & 234 & -64.62 \\
\hline RER Underval & -0.144 & 0.333 & 0.67 & 48 & 58 & 348 & -86.13 \\
\hline Trade Openness (de jure) & -1.019 & 0.304 & 0.00 & 43 & 52 & 316 & -74.89 \\
\hline Trade Openness (de facto) & 0.014 & 0.005 & 0.00 & 48 & 58 & 348 & -80.82 \\
\hline Current Account Balance & -0.000 & 0.027 & 1.00 & 27 & 34 & 222 & -47.79 \\
\hline Manufactures (\% Exports) & -0.015 & 0.007 & 0.04 & 24 & 31 & 236 & -42.26 \\
\hline$\Delta$ Terms of Trade & -0.007 & 0.017 & 0.68 & 24 & 27 & 164 & -36.63 \\
\hline Export Diversification & -0.015 & 0.008 & 0.07 & 24 & 31 & 236 & -42.29 \\
\hline Export Sophistication & -2.131 & 0.574 & 0.00 & 28 & 34 & 241 & -45.86 \\
\hline Capital Account Openness & -0.016 & 0.125 & 0.90 & 32 & 41 & 275 & -59.63 \\
\hline Financial Integration & 0.000 & 0.003 & 0.88 & 35 & 43 & 271 & -61.67 \\
\hline Financial Depth & -0.015 & 0.005 & 0.00 & 26 & 33 & 195 & -44.81 \\
\hline Financial Development & 0.006 & 0.009 & 0.55 & 31 & 39 & 266 & -57.87 \\
\hline External Debt Liabilities & 0.000 & 0.007 & 0.98 & 35 & 43 & 271 & -61.69 \\
\hline External Leverage & 0.003 & 0.014 & 0.82 & 35 & 43 & 271 & -61.64 \\
\hline FDI Liabilities & -0.004 & 0.018 & 0.83 & 35 & 43 & 271 & -61.67 \\
\hline Private Credit & -0.013 & 0.004 & 0.00 & 28 & 35 & 198 & -47.09 \\
\hline Polity IV Score & -0.064 & 0.018 & 0.00 & 47 & 57 & 346 & -80.27 \\
\hline Democracy Score & -0.118 & 0.032 & 0.00 & 47 & 57 & 346 & -80.43 \\
\hline Autocracy Score & 0.127 & 0.038 & 0.00 & 47 & 57 & 346 & -80.57 \\
\hline Executive Recruitment & -0.163 & 0.057 & 0.00 & 47 & 57 & 346 & -81.90 \\
\hline Executive Constraints $\left(I N S_{0}\right)$ & -0.218 & 0.065 & 0.00 & 47 & 57 & 346 & -79.70 \\
\hline Political Competition & -0.122 & 0.038 & 0.00 & 47 & 57 & 346 & -80.89 \\
\hline Regime Durability & -0.002 & 0.005 & 0.72 & 47 & 57 & 346 & -84.96 \\
\hline Corruption (ICRG) & -0.486 & 0.141 & 0.00 & 14 & 18 & 98 & -19.29 \\
\hline Fractionalization $(E L F 1)$ & 0.018 & 0.007 & 0.01 & 48 & 58 & 348 & -83.82 \\
\hline Fractionalization (ELF15) & 0.018 & 0.004 & 0.00 & 48 & 58 & 348 & -78.07 \\
\hline Inequality (Gini) & 0.045 & 0.023 & 0.05 & 22 & 27 & 137 & -34.73 \\
\hline Leader Exit & 0.424 & 0.360 & 0.24 & 47 & 57 & 346 & -84.18 \\
\hline War/Conflict (major) & 0.179 & 0.875 & 0.84 & 48 & 58 & 348 & -86.19 \\
\hline War/Conflict (any) & 0.469 & 0.553 & 0.40 & 48 & 58 & 348 & -85.73 \\
\hline Infant Mortality & 0.014 & 0.006 & 0.02 & 48 & 58 & 348 & -83.18 \\
\hline Life Expectancy & -0.060 & 0.030 & 0.05 & 48 & 58 & 348 & -83.03 \\
\hline Education (Primary) & -0.356 & 0.096 & 0.00 & 46 & 56 & 327 & -76.39 \\
\hline Education (Secondary) & -0.448 & 0.165 & 0.01 & 46 & 56 & 327 & -79.76 \\
\hline Education (All) & -0.254 & 0.063 & 0.00 & 46 & 56 & 327 & -76.17 \\
\hline Telephones per capita & -0.021 & 0.014 & 0.13 & 30 & 38 & 257 & -52.57 \\
\hline
\end{tabular}

Note(s): All models also include initial GDP per capita, the real US interest rate, and a constant. The standard errors are clustered on the country level. 



\section{The UNU-MERIT WORKING Paper Series}

2013-01 Effects of innovation on employment in Latin America by Gustavo Crespi and Ezequiel Tacsir

2013-02 Revisiting the porter hypothesis: An empirical analysis of green innovation for the Netherlands George van Leeuwen and Pierre Mohnen

2013-03 Impact of external knowledge acquisition strategies on innovation - A comparative study based on Dutch and Swiss panel data by Spyros Arvanitis, Boris Lokshin, Pierre Mohnen and Martin Wörter

2013-04 Interactive knowledge exchanges under complex social relations: A simulation modelRobin by Cowan and Anant Kamath

2013-05 Innovation systems framework: still useful in the new global context? by Michiko lizuka

2013-06 The importance of intrinsic and extrinsic motivation for measuring IQ by Lex Borghans, Huub Meijers and Bas ter Weel

2013-07 Firms' innovation capability-building paths and the nature of changes in learning mechanisms: Multiple case-study evidence from an emerging economy by Paulo N. Figueiredo, Marcela Cohen and Saulo Gomes

2013-08 A set of time series data labour market stocks and flows for the Netherlands 1980 to 2010 by Manuel Müllers, Joan Muysken and Erik de Regt

2013-09 Designing an optimal 'tech fix' path to global climate stability: R\&D in a multiphase climate policy framework by Adriaan van Zon and Paul A. David

2013-10 Complementarity between internal knowledge creation and external knowledge sourcing in developing countries by Jun Hou and Pierre Mohnen

2013-11 Summarizing large spatial datasets: Spatial principal components and spatial canonical correlation by Samyukta Bhupatiraju, Bart Verspagen and Thomas Ziesemer

2013-12 Regional systems of innovation in the Arab region by Samia Satti Osman Mohamed Nour

2013-13 Development and social justice: Education, training and health in Sudan by Samia Satti Osman Mohamed Nour

2013-14 The economic importance and impacts of intellectual property rights (IPRs) in Sudan by Samia Satti Osman Mohamed Nour

2013-15 Overview of knowledge economy in the Arab region by Samia Satti Osman Mohamed Nour

2013-16 The importance (impacts) of knowledge at the macro-micro levels in the Arab Gulf countries by Samia Satti Osman Mohamed Nour

2013-17 Political determinants and impact analysis of using a cable system as a complement to an urban transport system by Diego Escobar-García, Francisco García-Orozco and Carlos Cadena-Gaitán

2013-18 Women entrepreneurs in the informal economy: Is formalization the only solution for business sustainability? By Shyama V. Ramani, Ajay Thutupalli, Tamas Medovarszki, Sutapa Chattopadhyay, Veena Ravichandran

2013-19 Heterogeneity in innovation strategies, evolving consumer preferences and market structure: An evolutionary multi-agent based modelling approach by Salih Çevikarslan 
2013-20 Optimal patent length and patent breadth in an R\&D driven market with evolving consumer preferences: An evolutionary multi-agent based modelling approach by Salih Çevikarslan

2013-21 Innovation and productivity: An update by Pierre Mohnen and Bronwyn H. Hall 2013-22 Fathers' use of parental leave. What do we know? by Nevena Zhelyazkova

2013-23 Eliciting Illegal migration rates through list randomization by David McKenzie and Melissa Siegel

2013-24 How do ICT firms in Turkey manage innovation? Diversity in expertise versus diversity in markets by Semih Akçomak, Erdal Akdeve and Derya Fındık

2013-25 Dynamic models of R\&D, innovation and productivity: Panel data evidence for Dutch and French manufacturing by Wladimir Raymond, Jacques Mairesse, Pierre Mohnen and Franz Palm

2013-26 Centre-based versus home-based childcare by Robert Bauchmüller

2013-27 Microeconometric evidence of financing frictions and innovative activity by Amaresh K Tiwari, Pierre Mohnen, Franz C Palm and Sybrand Schim van der Loeff 2013-28 Innovation for economic performance: The case of Latin American firms by Elena Arias Ortiz, Gustavo Crespi, Ezequiel Tacsir, Fernando Vargas and Pluvia Zuñiga

2013-29 Is money all? Financing versus knowledge and demand constraints to innovation Gabriele Pellegrino and Maria Savona

2013-30 Child deprivation in Ontario - A (less than perfect) comparison with Europe by Geranda Notten

2013-31 Measuring performance: does the assessment depend on the poverty proxy? by Geranda Notten

2013-32 How big is the impact of infrastructure on trade? Evidence from meta-analysis by Mehmet Güney Celbis, Peter Nijkamp and Jacques Poot

2013-33 Using a 'Systems' Perspective to Explain the Limits of 'New' Multinational Enterprises: the role of 'members-only' location advantages by Rajneesh Narula

2013-34 Foreign direct investment as a driver of industrial development: why is there so little evidence? by Rajneesh Narula

2013-35 The end of the multifibre arrangement (MFA) and the heterogeneous performance of quota-constrained countries by Mulu Gebreeyesus

2013-36 Techological capability building in MNE-related social businesses of less developed countries: The experience of Grameen-Danone Foods in Bangladesh by Jahan A. Peerally and Paulo N. Figueiredo

2013-37 The links between economic integration and remittances behaviour of migrants in the Netherlands by Özge Bilgili

2013-38 The influence of vulnerability on migration intentions in Afghanistan by Craig Loschmann and Melissa Siegel

2013-39 How unemployment insurance savings accounts affect employment duration: Evidence from Chile by Paula Nagler

2013-40 Self-organization of knowledge economies by François Lafond

2013-41 Designing an optimal 'tech fix' path to global climate stability: Directed R\&D and embodied technical change in a multi-phase framework by Adriaan van Zon \& Paul A. David

2013-42 The growth of outward FDI and the competitiveness of the underlying economy: the case of India by Rajneesh Narula and Tiju Prasad Kodiyat 
2013-43 The impact of migration on children left behind in Moldova by Franziska Gassmann, Melissa Siegel, Michaella Vanore and Jennifer Waidler

2013-44 Technological spillovers and industrial growth in Chinese regions by Lili Wang, Huub Meijers and Adam Szirmai

2013-45 Male use of parental leave in Luxembourg: Empirical analysis of administrative records by Nevena Zhelyazkova

2013-46 Exploring the paradox of competence-creating subsidiaries: balancing bandwidth and dispersion in MNEs by Rajneesh Narula

2013-47 Switching off or switching source: energy consumption and household response to higher energy prices in the Kyrgyz Republic by Franziska Gassmann and Raquel Tsukada

2013-48 Beyond technological catch-up: An empirical investigation of further innovative capability accumulation outcomes in latecomer firms with evidence from Brazil by Paulo N. Figueiredo

2013-49 Parental leave within the broader work-family trajectory: What can we learn from sequence analysis? by Nevena Zhelyazkova

2013-50 Transnational corruption and innovation in transition economies by Alexis Habiyaremye and Wladimir Raymond

2013-51 The pace of poverty reduction - A fractional response approach by Richard Bluhm, Denis de Crombrugghe and Adam Szirmai

2013-52 Minding Weber more than ever? The impacts of State Capacity and Bureaucratic Autonomy on development goals by Luciana Cingolani, Kaj Thomsson and Denis de Crombrugghe

2013-53 The State of State Capacity: a review of concepts, evidence and measures by Luciana Cingolani

2013-54 Institutions, Foreign Direct Investment, and Domestic Investment: crowding out or crowding in? by Kristine Farla, Denis de Crombrugghe and Bart Verspagen

2013-55 Determinants of firms' investment behaviour: A multilevel approach by Kristine Farla

2013-56 Economic development, growth, institutions and geography by Samyukta Bhupatiraju \& Bart Verspagen

2013-57 Innovation and survival of new firms in Chinese manufacturing, 2000-2006 by Mingqian Zhang and Pierre Mohnen

2013-58 Government support, innovation and productivity in the Haidian (Beijing) district by Can Huang, Yilin Wu, Pierre Mohnen and Yanyun Zhao

2013-59 The impact of the 2009 value added tax reform on enterprise investment and employment - Empirical analysis based on Chinese tax survey data by Dehua Wang

2013-60 Doing R\&D in a closed or open mode: Dynamics and impacts on productivity by Julio Miguel Rosa and Pierre Mohnen

2013-61 Ethnic segregation and heterogeneous preferences of homeowners for housing and neighbourhood characteristics. Evidence from the Netherlands by Cheng Boon Ong and Kristof De Witte

2013-62 Promoting productive employment in Sub-Saharan Africa: A review of the literature by Adam Szirmai, Mulu Gebreeyesus, Francesca Guadagno and Bart Verspagen

2013-63 Estimation of rates of return on social protection: Making the case for noncontributory social transfers in Cambodia by Andrés Mideros, Franziska Gassmann and Pierre Mohnen 
2013-64 The influence of ethnic segregation and school mobility in primary education on high school dropout. Evidence from regression discontinuity at a contextual tipping point by Cheng Boon Ong and Kristof De Witte

2013-65 Bringing migration into the post-2015 agenda: Notes, reflections and policy directions by Ronald Skeldon

2013-66 What's the best place for me? Location-choice for S\&E students in India by Metka Hercog and Mindel van de Laar

2013-67 Determinants of international mobility decision: The case-study of India by Metka Hercog and Mindel van de Laar

2013-68 Social Media and Migration Research by Elaine McGregor and Melissa Siegel

2013-69 Do weak institutions prolong crises? On the identification, characteristics, and duration of declines during economic slumps Richard Bluhm, Denis de Crombrugghe and Adam Szirmai 